\title{
Symmetry-Related Transitions in the Spectrum of Nanosized Cubic $\mathrm{Y}_{2} \mathrm{O}_{3}: \mathrm{Tb}^{3+}$
}

\author{
Daniel den Engelsen, Paul G. Harris, Terry G. Ireland, ${ }^{\mathrm{Z}}$ George Fern, and Jack Silver \\ Centre for Phosphor and Display Materials, Wolfson Centre for Materials Processing, Brunel University London, \\ Uxbridge, Middlesex, UB8 3PH, United Kingdom
}

\begin{abstract}
Herein the preparation and cathodoluminescence of nanoparticles of cubic $\mathrm{Y}_{2} \mathrm{O}_{3}: \mathrm{Tb}^{3+}$ having $\mathrm{Tb}^{3+}$ concentration varying between 0.1 and $10 \mathrm{Mol} \%$ are described. The cathodoluminescence spectra were recorded with a high resolution spectrometer, which enabled the identification of $\mathrm{Tb}^{3+}$ lines with $\mathrm{C}_{2}$ and $\mathrm{S}_{6}$ symmetry: the lines at $542.8 \mathrm{~nm}$ and $544.4 \mathrm{~nm}$ were designated as ${ }^{5} \mathrm{D}_{4} \rightarrow{ }^{7} \mathrm{~F}_{5}\left(\mathrm{C}_{2}\right)$ and ${ }^{5} \mathrm{D}_{4} \rightarrow{ }^{7} \mathrm{~F}_{5}\left(\mathrm{~S}_{6}\right)$ respectively. The critical distance for energy transfer from $\mathrm{Tb}^{3+}$ ions at $\mathrm{S}_{6}$ lattice sites to $\mathrm{Tb}^{3+}$ ions at $\mathrm{C}_{2}$ lattice sites was found to be $>1.7 \mathrm{~nm}$. At the greater distances which prevail at low $\mathrm{Tb}^{3+}$ concentration, this energy transfer virtually stops. From cathodoluminescence spectra recorded in a scanning transmission electron microscope it was concluded that this energy transfer also did not take place if the temperature was reduced below $102 \mathrm{~K}$. The efficiency of the cathodoluminescence of $1 \% \mathrm{Y}_{2} \mathrm{O}_{3}: \mathrm{Tb}^{3+}$ was $6 \mathrm{~lm} / \mathrm{w}$ at a beam voltage of $15 \mathrm{kV}$. The decay time of the ${ }^{5} \mathrm{D}_{4} \rightarrow{ }^{7} \mathrm{~F}_{5}\left(\mathrm{C}_{2}\right)$ transition was substantially shorter than that of the ${ }^{5} \mathrm{D}_{4} \rightarrow{ }^{7} \mathrm{~F}_{5}\left(\mathrm{~S}_{6}\right)$ transition at low $\mathrm{Tb}^{3+}$ concentrations. The decay behavior of the cathodoluminescence images in a field emission scanning electron microscope has been explained in terms of phosphor saturation.

(c) The Author(s) 2015. Published by ECS. This is an open access article distributed under the terms of the Creative Commons Attribution 4.0 License (CC BY, http://creativecommons.org/licenses/by/4.0/), which permits unrestricted reuse of the work in any medium, provided the original work is properly cited. [DOI: 10.1149/2.0251507jss] All rights reserved.
\end{abstract}

Manuscript submitted March 16, 2015; revised manuscript received April 16, 2015. Published May 12, 2015.

Recently we have published a study on the cathodoluminescence (CL) of nanosized $\mathrm{Y}_{2} \mathrm{O}_{3}: \mathrm{Eu}^{3+}$ particles. ${ }^{1}$ The methods described in that report enabled a detailed analysis of the symmetry-related spectral transitions in the CL spectrum of $\mathrm{Y}_{2} \mathrm{O}_{3}: \mathrm{Eu}^{3+}$. In the present report we describe a study on the cathodoluminescence of nanosized $\mathrm{Y}_{2} \mathrm{O}_{3}: \mathrm{Tb}^{3+}$ particles using the same methods as developed for analyzing the spectra of $\mathrm{Y}_{2} \mathrm{O}_{3}: \mathrm{Eu}^{3+}$. Although the industrial importance of $\mathrm{Y}_{2} \mathrm{O}_{3}: \mathrm{Tb}^{3+}$ is smaller than that of $\mathrm{Y}_{2} \mathrm{O}_{3}: \mathrm{Eu}^{3+}$, the strong green fluorescence of $\mathrm{Tb}^{3+}$ doped $\mathrm{Y}_{2} \mathrm{O}_{3}$ crystals has attracted much attention and many scientists studied the PL and CL spectra of $\mathrm{Y}_{2} \mathrm{O}_{3}: \mathrm{Tb}^{3+}$ particles, both micrometre and nanometre sized. The CL spectra of nine rare earth ions in $\mathrm{Y}_{2} \mathrm{O}_{3}$ host crystals were published by Ozawa. ${ }^{2}$ The idiosyncrasy of the luminescence spectra of $\mathrm{Tb}^{3+}$ doped phosphors was nicely summarized by Blasse and Grabmaier: domination by the ${ }^{5} \mathrm{D}_{4} \rightarrow{ }^{7} \mathrm{~F}_{\mathrm{J}}$ $\left(\mathrm{J}=2,3,4,5\right.$ and 6) transitions, contribution of (weak) ${ }^{5} \mathrm{D}_{3} \rightarrow{ }^{7} \mathrm{~F}_{\mathrm{J}}$ transitions in the blue and a complicated structure of the crystal field splitting because of the rather high J quantum numbers. ${ }^{3}$

Figure 1 shows the high resolution CL spectrum of cubic nanosized $\mathrm{Y}_{2} \mathrm{O}_{3}: \mathrm{Tb}^{3+}$ with $1 \% \mathrm{~Tb}^{3+}$ recorded by us at an electron energy of $15 \mathrm{keV}$, current density of $2 \mu \mathrm{A} / \mathrm{cm}^{2}$ and room temperature. The spectral radiance of the ${ }^{5} \mathrm{D}_{3} \rightarrow{ }^{7} \mathrm{~F}_{\mathrm{J}}$ transitions in the blue region of the spectrum is very small and cannot be observed in Figure 1. The inset shows a detail of the spectrum between $535 \mathrm{~nm}$ and $560 \mathrm{~nm}$ : 10 peaks can be observed at these conditions. Because of the complicated configuration of the peaks in the various ${ }^{5} \mathrm{D}_{4} \rightarrow{ }^{7} \mathrm{~F}_{\mathrm{J}}$ transition clusters, a detailed designation of the lines to specific crystal-field-splitting levels has not been established. A second complication in identifying the spectral lines of $\mathrm{Y}_{2} \mathrm{O}_{3}: \mathrm{Tb}^{3+}$ is related to the crystal structure of the $\mathrm{Y}_{2} \mathrm{O}_{3}$-host. It has been well established that $\mathrm{Y}_{2} \mathrm{O}_{3}$ doped with various concentrations of $\mathrm{Tb}^{3+}$ and annealed at temperatures above $900^{\circ} \mathrm{C}$ has the cubic structure of the mineral bixbyite $;^{4-10}$ moreover, the cell constant of the unit cell, $1.060 \mathrm{~nm}$, does not change upon doping. ${ }^{6}$ This cubic structure has two different $\mathrm{Y}^{3+}$ lattice sites, which possess the point symmetries $\mathrm{C}_{2}$ and $\mathrm{S}_{6}$ : 24 lattice sites have $\mathrm{C}_{2}$ symmetry, while the other 8 have $S_{6}$ symmetry. ${ }^{11}$ These sites are shown in Figure 2. Upon doping $\mathrm{Y}_{2} \mathrm{O}_{3}$ with $\mathrm{Tb}^{3+}$ the two sites are occupied with $\mathrm{Tb}^{3+}$ with almost equal probability, because the $\mathrm{Tb}^{3+}$ ion is only slightly smaller than the $\mathrm{Y}^{3+}$ ion: hence, the concentration of $\mathrm{Tb}^{3+}$ at $C_{2}$ sites will be three times larger than the concentration of $\mathrm{Tb}^{3+}$ at $S_{6}$ sites. It can be seen that the $S_{6}$ sites have inversion symmetry, whereas the $\mathrm{C}_{2}$ sites exhibit a "small deviation" from the inversion symmetry according to Blasse and Grabmaier. ${ }^{3}$ Unlike the situation

${ }^{\text {zE} E-m a i l: ~ t e r r y . i r e l a n d @ b r u n e l . a c . u k ~}$ for the $\mathrm{Y}_{2} \mathrm{O}_{3}: \mathrm{Eu}^{3+}$ spectrum, in which various $\mathrm{S}_{6}$ and $\mathrm{C}_{2}$ lines have been identified, an identification of symmetry-related peaks in the spectrum of $\mathrm{Y}_{2} \mathrm{O}_{3}: \mathrm{Tb}^{3+}$ is missing. As we have shown in our study of the CL-spectrum of $\mathrm{Y}_{2} \mathrm{O}_{3}: \mathrm{Eu}^{3+}$, the relation between $\mathrm{C}_{2}$ and $\mathrm{S}_{6}$ transitions gave valuable information on the energy transfer between levels in $\mathrm{Eu}^{3+}$. In order to make a similar analysis for $\mathrm{Y}_{2} \mathrm{O}_{3}: \mathrm{Tb}^{3+}$, we need to identify $\mathrm{C}_{2}$ and $\mathrm{S}_{6}$ transitions in the spectrum.

In spite of the absence of any assignment of the lines in the various ${ }^{5} \mathrm{D}_{4} \rightarrow{ }^{7} \mathrm{~F}_{\mathrm{J}}$ transition clusters, the scientific work on nanosized $\mathrm{Y}_{2} \mathrm{O}_{3}: \mathrm{Tb}^{3+}$ is progressing. ${ }^{5-10,12-16}$ The majority of these recent studies have dealt with photoluminescence (PL) of $\mathrm{Y}_{2} \mathrm{O}_{3}: \mathrm{Tb}^{3+}$; however, Alarcón-Flores et al. ${ }^{12}$ and Cho et al. ${ }^{13}$ have used cathodoluminescence (CL), while Cress et al. ${ }^{14}$ have applied alpha particles (radioluminescence) to excite the phosphor. In the PL studies the effects of annealing temperature, particle size and $\mathrm{Tb}^{3+}$ concentration in the $\mathrm{Y}_{2} \mathrm{O}_{3}$ host have been described. Most authors discussed the cross relaxation of the $5 \mathrm{~d}$ and $4 \mathrm{f}$ levels of $\mathrm{Tb}^{3+}$; however, Withnall et al. ${ }^{15}$ suggested also the possibility of energy transfer between $\mathrm{Tb}^{3+}$ at an $\mathrm{S}_{6}$ and a $\mathrm{C}_{2}$ site in cubic $\mathrm{Y}_{2} \mathrm{O}_{3}$. Meng et al. ${ }^{7}$ attributed the differences between excitation spectra to surface versus bulk effects upon changing the $\mathrm{Y}_{2} \mathrm{O}_{3}: \mathrm{Tb}^{3+}$ particle size. Goldburt et al. ${ }^{16}$ found that the PL efficiency decreased by a factor of 5 when the size of the nano particles increased from 4 to $9 \mathrm{~nm}$. Liu et al. ${ }^{8}$ studied the effect of $\mathrm{Eu}^{3+}$, $\mathrm{Tb}^{3+}$ co-doping on the luminescent properties of $\mathrm{Y}_{2} \mathrm{O}_{3}$ nanorods as a function of the $\mathrm{Tb}^{3+}$ concentration. Chien et al. ${ }^{5}$ found that $1 \mathrm{Mol} \%$ $\mathrm{Tb}^{3+}$ in $\mathrm{Y}_{2} \mathrm{O}_{3}$ has the highest PL efficiency, Jiu et al. ${ }^{9}$ found that a concentration of $3 \%$ was optimum whereas Park et al. ${ }^{10}$ concluded that $8 \% \mathrm{~Tb}^{3+}$ was most efficient. Sotiriou et al. ${ }^{4}$ described the effect of the lattice on the PL efficiency. They found that monoclinic $\mathrm{Y}_{2} \mathrm{O}_{3}: \mathrm{Tb}^{3+}$ has a higher efficiency than the cubic phase, which needs a higher annealing temperature. This brief review of recent work on the luminescence of nanosized $\mathrm{Y}_{2} \mathrm{O}_{3}: \mathrm{Tb}^{3+}$ is in no way exhaustive; however, it does illustrate the widespread interest in this material.

The objective of this study is analyzing the CL-spectra and decay behavior of some transitions of nanosized $\mathrm{Y}_{2} \mathrm{O}_{3}: \mathrm{Tb}^{3+}$ in the hope to find evidence for a symmetry-related route of energy transfer beside the well-known relaxation between the ${ }^{5} \mathrm{D}_{3}$ and ${ }^{7} \mathrm{~F}_{6}$ levels. ${ }^{17} \mathrm{In}$ our previous study ${ }^{1}$ on the energy transfer in nanosized $\mathrm{Y}_{2} \mathrm{O}_{3}: \mathrm{Eu}^{3+}$ we could confirm the results obtained with micrometer-sized particles. ${ }^{18}$ So, we assume that the size of the particles is not the determining parameter for this study, but rather the concentration of $\mathrm{Tb}^{3+}$ in the $\mathrm{Y}_{2} \mathrm{O}_{3}$ lattice. To make a fair comparison between the spectra of different $\mathrm{Tb}^{3+}$ concentrations in $\mathrm{Y}_{2} \mathrm{O}_{3}$, temperature, current density and e-beam energy were kept constant. Deviations from this principle are indicated in the text. 


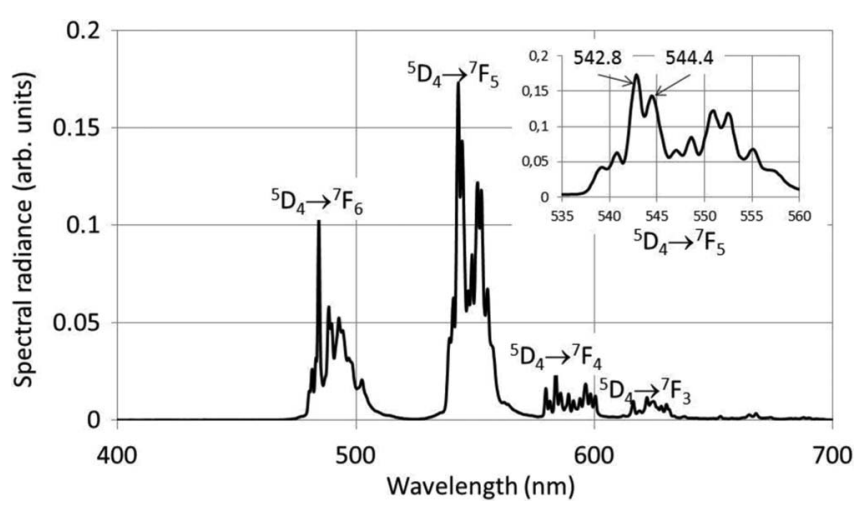

Figure 1. High resolution CL spectrum of cubic nanosized $\mathrm{Y}_{2} \mathrm{O}_{3}: \mathrm{Tb}^{3+}$ with $1 \mathrm{Mol} \% \mathrm{~Tb}^{3+}$ recorded at a beam energy of $15 \mathrm{keV}$, current density of $2 \mu \mathrm{A} / \mathrm{cm}^{2}$ and room temperature. Inset: ${ }^{5} \mathrm{D}_{4} \rightarrow{ }^{7} \mathrm{~F}_{4}$ transition cluster in wide wavelength scale. The wavelengths (in $\mathrm{nm}$ ) of the two strongest peaks in the spectrum are indicated.

\section{Materials and Methods}

Materials and synthesis.- Yttrium oxide (99.99\%, Ampere Industrie, France) and terbium oxide (99.99\%, Neo performance materials, UK) were used to prepare the terbium-doped yttrium nitrate stock solutions. Urea, nitric acid and isopropanol (IPA) were supplied by Fisher Scientific, UK; all chemicals were used as received. Glass substrates $\left(1 \mathrm{~cm}^{2}\right)$ coated with an indium tin oxide (ITO) film $(85 \Omega / s q)$ were obtained from Visiontek Ltd., UK. The ITO-coated slides were carefully cleaned in de-ionized water and IPA using ultrasonic cavitation. Conductive carbon tabs coated with adhesive on both sides were used as substrate for recording the spectra and the imaging studies in the field emission scanning electron microscope (FESEM). For the transmission electron microscope (TEM) special Cgrid substrates were used. The synthesis of $\mathrm{Y}_{2} \mathrm{O}_{3}: \mathrm{Eu}^{3+}$ nanoparticles by the urea method has been described extensively in our earlier work; ${ }^{1,19-21}$ the synthesis of nanosized $\mathrm{Y}_{2} \mathrm{O}_{3}: \mathrm{Tb}^{3+}$ was done identically. The aging of the turbid suspensions after the onset of precipitation was continued for one hour at a temperature above $85^{\circ} \mathrm{C}$ (which is the temperature at which urea slowly decomposes in aqueous media). After this aging period the precipitate was filtered, washed three times with de-ionized water and dried in an oven at $80^{\circ} \mathrm{C}$. The phosphor precursor particles were then annealed at $980^{\circ} \mathrm{C}$ in a furnace in air for four hours to yield cubic nanosized $\mathrm{Y}_{2} \mathrm{O}_{3}: \mathrm{Tb}^{3+}$ phosphor particles. This annealing temperature guarantees cubic crystallites that yield optimum CL characteristics. ${ }^{20}$ The $\mathrm{Y}_{2} \mathrm{O}_{3}: \mathrm{Tb}^{3+}$ powders after annealing looked slightly yellow-brown, due to the presence of a small quantity of $\mathrm{Tb}^{4+} .22$ The possible reduction of this very small quantity of $\mathrm{Tb}^{4+}$ will be discussed in the CL spectrum section.

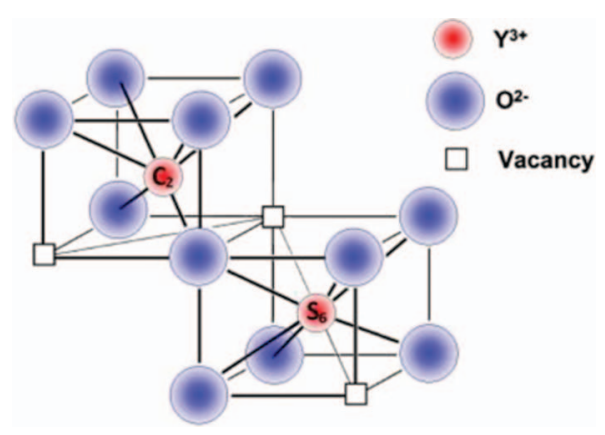

Figure 2. $\mathrm{C}_{2}$ and $\mathrm{S}_{6}$ sites of the $\mathrm{Y}^{3+}$ cation in cubic $\mathrm{Y}_{2} \mathrm{O}_{3} . \mathrm{S}_{6}$ has inversion symmetry, whereas $\mathrm{C}_{2}$ has $180^{\circ}$ rotation symmetry.
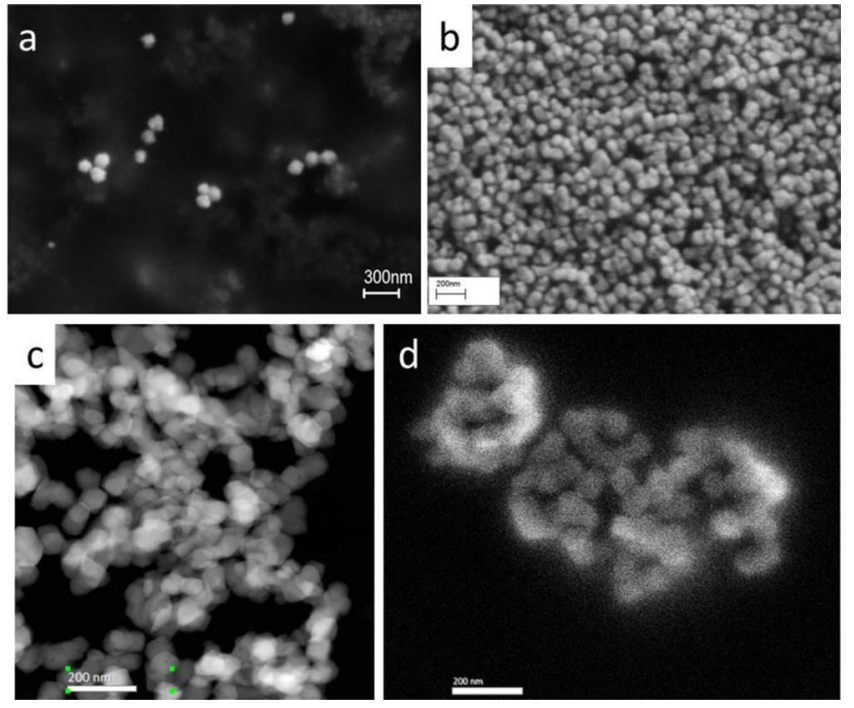

Figure 3. (a) FESEM image of $\mathrm{Y}_{2} \mathrm{O}_{3}: \mathrm{Tb}^{3+}\left(0.3 \% \mathrm{~Tb}^{3+}\right)$ particles on $\mathrm{C}$ substrate $(10 \mathrm{kV})$. (b) FESEM image of dense layer of $\mathrm{Y}_{2} \mathrm{O}_{3}: \mathrm{Tb}^{3+}(10 \%$ $\left.\mathrm{Tb}^{3+}\right)$ on $\mathrm{Si}$ substrate. (c) STEM image of $\mathrm{Y}_{2} \mathrm{O}_{3}: \mathrm{Tb}^{3+}\left(3 \% \mathrm{~Tb}^{3+}\right)$ at 200 $\mathrm{kV}$ on C-substrate. (d) Panchromatic cathodoluminescence STEM image of $\mathrm{Y}_{2} \mathrm{O}_{3}: \mathrm{Tb}^{3+}\left(3 \% \mathrm{~Tb}^{3+}\right)$ at $200 \mathrm{kV}$ on C-substrate.

Phosphor layers were deposited onto ITO-coated glass slides by electrophoresis from isopropanol suspensions containing various phosphor concentrations; however, it was difficult to obtain uniform layers with an area of $1 \mathrm{~cm}^{2}$. Only layers with 3 and $1 \% \mathrm{~Tb}^{3+}$ had sufficient uniformity and could be used for the measurements of the luminous efficiency. Figure $3 \mathrm{a}$ shows a SEM image of $\mathrm{Y}_{2} \mathrm{O}_{3}: \mathrm{Tb}^{3+}$ $\left(0.3 \% \mathrm{~Tb}^{3+}\right)$ particles on a C-substrate. The scarce coverage of particles on the $\mathrm{C}$-substrate in Figure $3 \mathrm{a}$ was made on purpose to enable decay measurements in the SEM, to be discussed in Decay analysis with FESEM section. Figure $3 b$ shows an image of a settled layer of $\mathrm{Y}_{2} \mathrm{O}_{3}: \mathrm{Tb}^{3+}$ on a Si substrate, while Figures $3 \mathrm{c}$ and $3 \mathrm{~d}$ show TEM images of $\mathrm{Y}_{2} \mathrm{O}_{3}: \mathrm{Tb}^{3+}$ with $3 \% \mathrm{~Tb}^{3+}$. From Figures $3 b, 3 c$ and $3 d$ it can be derived that the average diameter of the $\mathrm{Y}_{2} \mathrm{O}_{3}: \mathrm{Tb}^{3+}$ particles varied between 50 and $80 \mathrm{~nm}$, which did not depend on the concentration of $\mathrm{Tb}^{3+}$, it was virtually equal for all concentrations. This particle diameter is much smaller than the identically synthesized $\mathrm{Y}_{2} \mathrm{O}_{3}: \mathrm{Eu}^{3+}$ particles, which showed spherical shapes with diameters ranging from $200 \mathrm{~nm}$ up to $350 \mathrm{~nm} .{ }^{1,19,20}$ These differences in size and shape could be caused by a (small) difference between the $\mathrm{pH}$ of the stock solutions of $\mathrm{Tb}\left(\mathrm{NO}_{3}\right)_{3}$ and $\mathrm{Eu}\left(\mathrm{NO}_{3}\right)_{3}$ : this will be the topic of a future study in our laboratory.

Equipment and methods.- The CL measurements were carried out using two high vacuum chamber systems. The first system, called herein as $5 \mathrm{kV}$ rig, was equipped with an EFG-7 electron gun with a maximum voltage of $5 \mathrm{kV}$ and a EGPS-7 power supply (both Kimball Physics Inc., USA) worked at a pressure of $4 \times 10^{-6}$ mbar. In this system decay measurements at current densities of typically $0.5 \mathrm{~mA} / \mathrm{cm}^{2}$ were conducted and some high resolution spectra as a function of current density up to $5 \mathrm{~mA} / \mathrm{cm}^{2}$ were recorded as well. On the second high vacuum chamber system, called $15 \mathrm{kV}$ rig, CL spectra were collected over a range of electron beam accelerating voltages from 3 to $15 \mathrm{kV}$ using an EFG-12 electron gun and EGPS-12 power supply (both Kimball Physics Inc., USA). The luminous efficiency measurements and recording of the CL spectra were done on the $15 \mathrm{kV}$ rig at current densities of $1-5 \mu \mathrm{A} / \mathrm{cm}^{2}$ and pressure of $2 \times 10^{-6}$ mbar. Deflection plates enabled optimum positioning of the electron beam on the sample and a $\mathrm{ZnO}: \mathrm{Zn}$ standard. The latter being a non-charging thin film of $\mathrm{ZnO}: \mathrm{Zn}$ powder on ITO-coated glass to adjust the current density on the charging $\mathrm{Y}_{2} \mathrm{O}_{3}: \mathrm{Tb}^{3+}$ samples as explained in our previous work. ${ }^{1,19}$ High resolution CL emission spectra of the samples were 


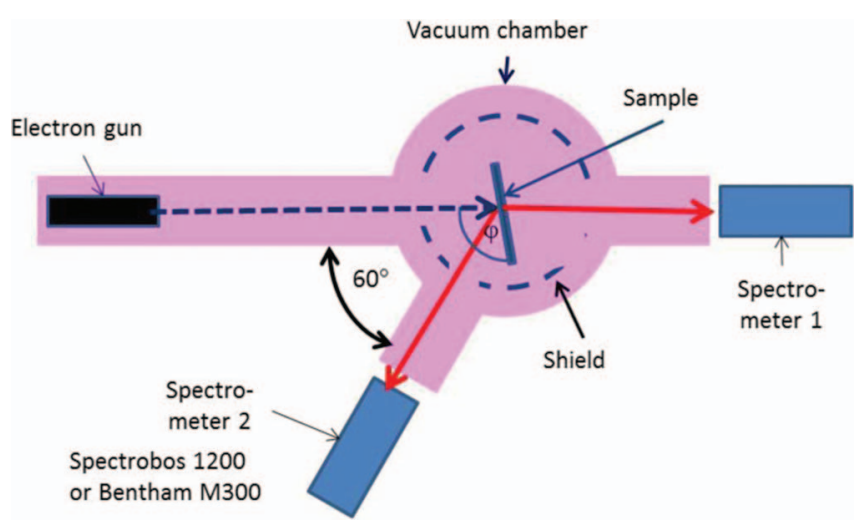

Figure 4. Equipment for CL measurements using two spectrometers. Recording of high resolution spectra with the Bentham monochromator was only done in reflection mode.

collected using a Bentham phosphor spectrometer system (Bentham Instruments Ltd., Reading, UK.), configured with M300 excitation and emission monochromators, to which the emission monochromator was connected via a fibre optic bundle positioned at the window of the vacuum chamber. The absolute wavelength calibration of this emission monochromator could be off by maximally $0.4 \mathrm{~nm}$; however, relative wavelength values were accurate within $0.03 \mathrm{~nm}$.

The electron gun set-up and viewing port geometries of the $15 \mathrm{kV}$ rig are shown in Figure 4. The sample was positioned in the centre of the vacuum chamber. For the determination of the luminous efficiency, spectral radiance and luminance were recorded with two Spectrobos 1200 spectroradiometers manufactured by JETI (Germany) between $380 \mathrm{~nm}$ and $780 \mathrm{~nm}$ in reflection and transmission mode, indicated in Figure 4 by spectrometers 2 and 1 respectively. Spectrometer 2 was replaced with the Bentham fibre optic bundle for recording the high resolution CL spectra.

The shield is a high transmission grid (transmission $>99 \%$ ) which is biased at $-50 \mathrm{~V}$ to collect all secondary electrons on the sample plate. By blanking the e-beam of the Kimball electron gun of the $5 \mathrm{kV}$ rig we could measure the persistence of the luminescence of various spectral transitions in $\mathrm{Y}_{2} \mathrm{O}_{3}: \mathrm{Tb}^{3+}$. The high resolution Bentham monochromator was used to adjust the wavelength to the maximum of a spectral peak. This measuring method has been described in detail in our previous report. ${ }^{1}$

The morphology and particle size assessment of the phosphor powders and CL-microscopy analyses were conducted in both a SEM and TEM. The SEM was a FESEM, Supra 35 VP, Carl Zeiss, Germany. Besides three detectors for secondary and backscattered electrons, this microscope was also equipped with a detector for CL. This facility enabled luminescence decay studies of individual phosphor particles, as we have recently described. ${ }^{1,23}$ Image analysis of the panchromatic CL-micrographs was performed using ImageJ (Public Domain) software.

The nanosized $\mathrm{Y}_{2} \mathrm{O}_{3}: \mathrm{Tb}^{3+}$ samples with 0.3 and $3 \% \mathrm{~Tb}^{3+}$ were also analyzed with a TEM, model $2100 \mathrm{~F}$, JEOL, Japan. This microscope was operated in scanning mode with a spot size of $0.2 \mathrm{~nm}$ or $1.5 \mathrm{~nm}$. The TEM was equipped with a Vulcan CL detector, Gatan, USA, for imaging and spectroscopic purposes. This system used a Czerny-Turner spectrometer with back-illuminated CCD and a grating with 1200 lines $/ \mathrm{mm}$ (blazed at $500 \mathrm{~nm}$ ) for collection of CL emission spectra. A cooled photo-multiplier tube (PMT) was utilized for collection of the total light flux from the sample. By collecting the visible light with the Vulcan system simultaneously with the JEOL high angle annular dark field detector it was possible to observe the visible light that was emitted from the particles. A small cryostat connected to the sample holder enabled cooling of the samples in the TEM down to $103 \mathrm{~K}\left(-170^{\circ} \mathrm{C}\right)$; adjustment of the sample temperature anywhere between $102 \mathrm{~K}$ and $303 \mathrm{~K}$ could be made.

\section{Results}

CL spectrum.- Figure 1 is the high resolution CL spectrum of nanosized $\mathrm{Y}_{2} \mathrm{O}_{3}: \mathrm{Tb}^{3+}$ with $1 \% \mathrm{~Tb}^{3+}$, recorded at the $15 \mathrm{kV}$ rig at low current density. The inset of this Figure shows the ${ }^{5} \mathrm{D}_{4} \rightarrow{ }^{7} \mathrm{~F}_{4}$ transition cluster at a wide wavelength scale. The two strongest peaks reach their maximum values at $542.8 \mathrm{~nm}$ and $544.4 \mathrm{~nm}$. Figure 5 shows normalized CL spectra of nanosized $\mathrm{Y}_{2} \mathrm{O}_{3}: \mathrm{Tb}^{3+}$ with $0.3,0.7$, 1 and $3 \% \mathrm{~Tb}^{3+}$, recorded at an electron energy of $15 \mathrm{keV}$, current density of $2 \mu \mathrm{A} / \mathrm{cm}^{2}$ and room temperature For reasons of clarity the spectra of the $0.1,0.6$ and $10 \% \mathrm{~Tb}^{3+}$ have not been included in Figure 5; the spectra for 0.1 and $10 \% \mathrm{~Tb}^{3+}$ are presented in Figure 6. Normalization was done versus the strongest peak in the spectra, viz. the $542.8 \mathrm{~nm}$ peak was set to unity in all spectra: this facilitated the comparison between the spectra. Figure 5 a refers to the ${ }^{5} \mathrm{D}_{4} \rightarrow{ }^{7} \mathrm{~F}_{5}$ the transition cluster, Figure $5 \mathrm{~b}$ to ${ }^{5} \mathrm{D}_{4} \rightarrow{ }^{7} \mathrm{~F}_{6}$, Figure $5 \mathrm{c}$ to ${ }^{5} \mathrm{D}_{4} \rightarrow{ }^{7} \mathrm{~F}_{3}$ and Figure $5 \mathrm{~d}$ to ${ }^{5} \mathrm{D}_{4} \rightarrow{ }^{7} \mathrm{~F}_{4}$. It can be seen that only Figures $5 \mathrm{a}$ and $5 \mathrm{c}$ show pronounced concentration effects; the concentration effects in the ${ }^{5} \mathrm{D}_{4} \rightarrow{ }^{7} \mathrm{~F}_{6}$ and ${ }^{5} \mathrm{D}_{4} \rightarrow{ }^{7} \mathrm{~F}_{4}$ transitions clusters are rather small, but cannot be neglected either. The isolated peak at $637.8 \mathrm{~nm}$ in the ${ }^{5} \mathrm{D}_{4} \rightarrow{ }^{7} \mathrm{~F}_{3}$ transition cluster, indicated by an arrow in Fig. $5 \mathrm{c}$, shows a particularly large effect: the $3 \% \mathrm{~Tb}^{3+}$ concentration has the lowest spectral radiance and the $0.3 \% \mathrm{~Tb}^{3+}$ the highest. The other concentrations have intermediate radiances. The same trend can be observed in the ${ }^{5} \mathrm{D}_{4} \rightarrow{ }^{7} \mathrm{~F}_{5}$ transition cluster notably for the peak at $544.4 \mathrm{~nm}$. Because of the low spectral radiance of the ${ }^{5} \mathrm{D}_{4} \rightarrow{ }^{7} \mathrm{~F}_{3}$ transitions cluster we did not analyze this part of the spectrum in detail and focussed on the high radiance ${ }^{5} \mathrm{D}_{4} \rightarrow{ }^{7} \mathrm{~F}_{5}$ peaks at $542.8 \mathrm{~nm}$ and $544.4 \mathrm{~nm}$. The normalized spectra did not change between 5 and $15 \mathrm{kV}$.

Figure 6 shows the CL spectra of the ${ }^{5} \mathrm{D}_{4} \rightarrow{ }^{7} \mathrm{~F}_{5}$ the transition cluster of $\mathrm{Y}_{2} \mathrm{O}_{3}: \mathrm{Tb}^{3+}$ with 0.1 and $10 \% \mathrm{~Tb}^{3+}$. The radiance was small for these samples because of considerable concentration quenching for the $10 \%$ sample and low concentration for the $0.1 \%$ sample. The spectra shown in Figure 6 are also normalized to unity at $542.8 \mathrm{~nm}$. For the $0.1 \%$ sample the $544.4 \mathrm{~nm}$ peak is now larger than the $542.8 \mathrm{~nm}$ peak. The spectrum of $6 \% \mathrm{~Tb}^{3+}$ is not shown, because it almost coincides with that of the $10 \%$ sample. The height difference of the $544.4 \mathrm{~nm}$ peak between 0.1 and $10 \% \mathrm{~Tb}^{3+}$ is very pronounced in this Figure. However, some peaks at $\lambda>544.4 \mathrm{~nm}$ show also substantial concentration effects.

The spectra shown in Figures 5 and 6 were recorded at a low current density between $2 \mu \mathrm{A} / \mathrm{cm}^{2}$ and $5 \mu \mathrm{A} / \mathrm{cm}^{2}$, in which the effect of saturation can be excluded. For the spectra shown in Figure 6 we used $5 \mu \mathrm{A} / \mathrm{cm}^{2}$ to increase the signal to noise ratio. We have also recorded CL-spectra of $\mathrm{Y}_{2} \mathrm{O}_{3}: \mathrm{Tb}^{3+}$ at much higher current density on the $5 \mathrm{kV}$ rig, in which the effect of current density becomes quite noticeable. An example is shown in Figure 7 for the ${ }^{5} \mathrm{D}_{4} \rightarrow{ }^{7} \mathrm{~F}_{5}$ transition cluster of $1 \%$ $\mathrm{Y}_{2} \mathrm{O}_{3}: \mathrm{Tb}^{3+}$, in which the $542.8 \mathrm{~nm}$ peak has again been normalized to unity. It can be seen that the peak at $544.4 \mathrm{~nm}$ suffers more from saturation than the peak at $542.8 \mathrm{~nm}$.

Because of the substantial overlapping of peaks in the spectra, comparing the peak values at $542.8 \mathrm{~nm}$ and $544.4 \mathrm{~nm}$ may yield inaccurate information; therefore, it was decided to calculate the ratio of the peaks at $542.8 \mathrm{~nm}$ and $544.4 \mathrm{~nm}$, indicated by $\mathrm{I}_{542.8} / \mathrm{I}_{544.4}$, from the deconvoluted spectra. The deconvolution was done in the same way as we did for the spectra of $\mathrm{Y}_{2} \mathrm{O} 3: \mathrm{Eu}^{3+}$ as described in Ref. 1. It was assumed that the spectral transitions have Gaussian shapes. The spectral radiance $\operatorname{SR}(\lambda)$, where $\lambda$ represents the wavelength, can be written as:

$$
S R(\lambda)=\sum_{i} A_{i} e^{\frac{-\left(\lambda-\lambda_{i}\right)^{2}}{s_{i}}},
$$

where $A_{i}$ is the maximum spectral radiance of the $i^{\text {th }}$ peak, $\lambda_{i}$ is the wavelength for the maximum and $\mathrm{s}_{\mathrm{i}}$ is a parameter related to the width of the $\mathrm{i}^{\text {th }}$ peak. The full width at half maximum (FWHM) is

$$
F W H M_{i}=1.665 \sqrt{s_{i}},
$$



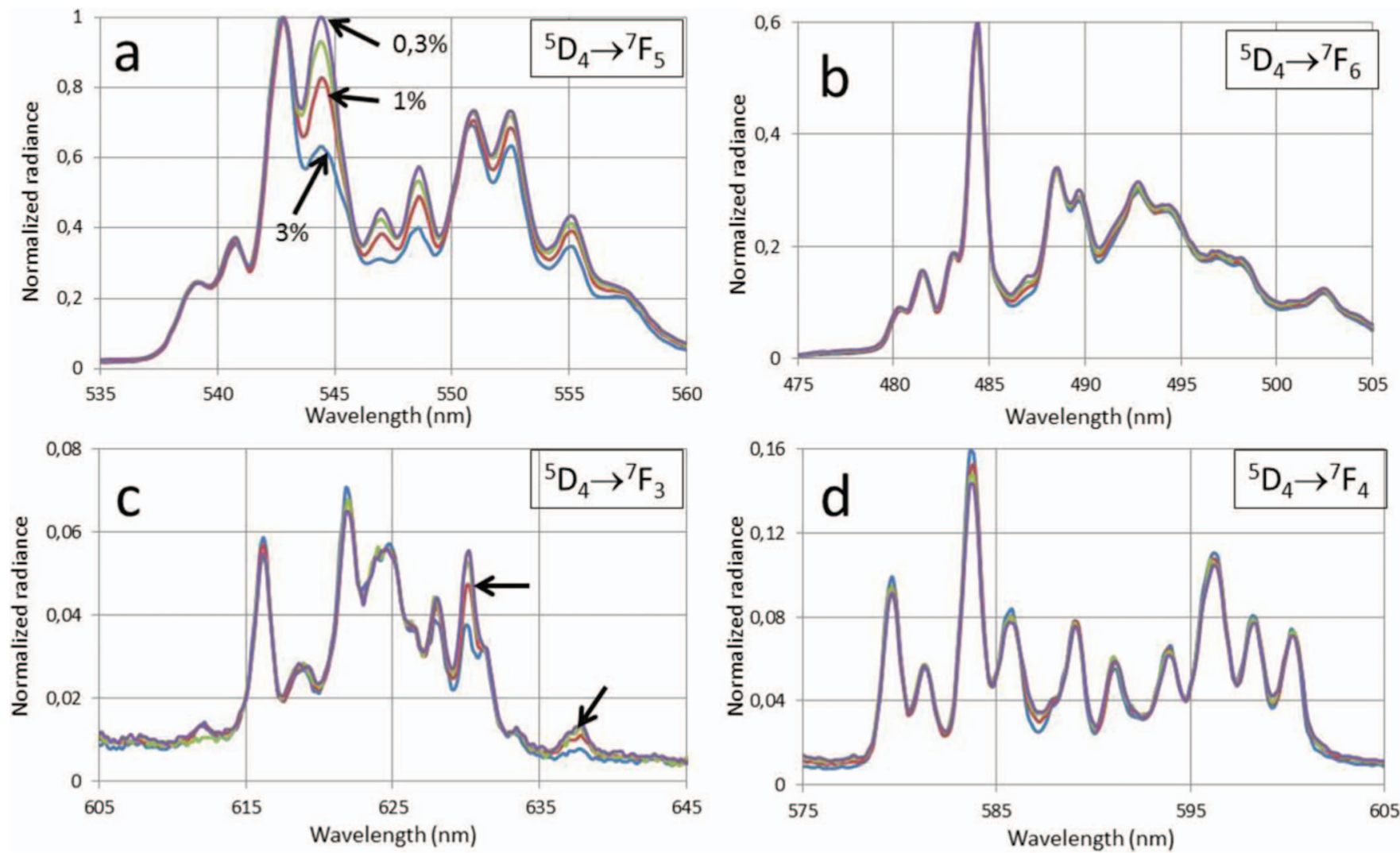

Figure 5. Normalized CL spectra of $\mathrm{Y}_{2} \mathrm{O}_{3}: \mathrm{Tb}^{3+}$ at $0.3,0.7,1$ and $3 \% \mathrm{~Tb}^{3+}$; a: ${ }^{5} \mathrm{D}_{4} \rightarrow{ }^{7} \mathrm{~F}_{5}$ cluster; b: ${ }^{5} \mathrm{D}_{4} \rightarrow{ }^{7} \mathrm{~F}_{6}$ cluster; c: ${ }^{5} \mathrm{D}_{4} \rightarrow{ }^{7} \mathrm{~F}_{3}$ cluster; d: ${ }^{5} \mathrm{D}_{4} \rightarrow{ }^{7} \mathrm{~F}_{4}$ cluster. Radiance of $542.8 \mathrm{~nm}$ peak set to unity for all spectra.

and the radiance of the $\mathrm{i}^{\text {th }}$ transition is

$$
R_{i}=\int_{-\infty}^{\infty} A_{i} e^{\frac{-\left(\lambda-\lambda_{i}\right)^{2}}{s_{i}}} d \lambda=A_{i} \sqrt{\pi s_{i}}
$$

An example of the deconvolution of the ${ }^{5} \mathrm{D}_{4} \rightarrow{ }^{7} \mathrm{~F}_{5}$ peaks at $542.8 \mathrm{~nm}$ and $544.4 \mathrm{~nm}$ is depicted in Figure 8 for $0.3 \% \mathrm{Y}_{2} \mathrm{O}_{3}: \mathrm{Tb}^{3+}$. In this deconvolution four Gaussian profiles were used; Lorentzian profiles did not yield satisfactory results. These four Gaussians were fitted to the experimental spectrum with a least squares algorithm using Microsoft's Excel solver.

The radiance ratio $\mathrm{I}_{542.8} / \mathrm{I}_{544.4}$ is plotted in Figure $9 \mathrm{a}$ as function of $\mathrm{Tb}^{3+}$ concentration and as a function of the average distance between $\mathrm{Tb}^{3+}$ ions in the $\mathrm{Y}_{2} \mathrm{O}_{3}$ lattice in Figure $9 \mathrm{~b}$. This average distance $\mathrm{D}_{\mathrm{Tb}}$

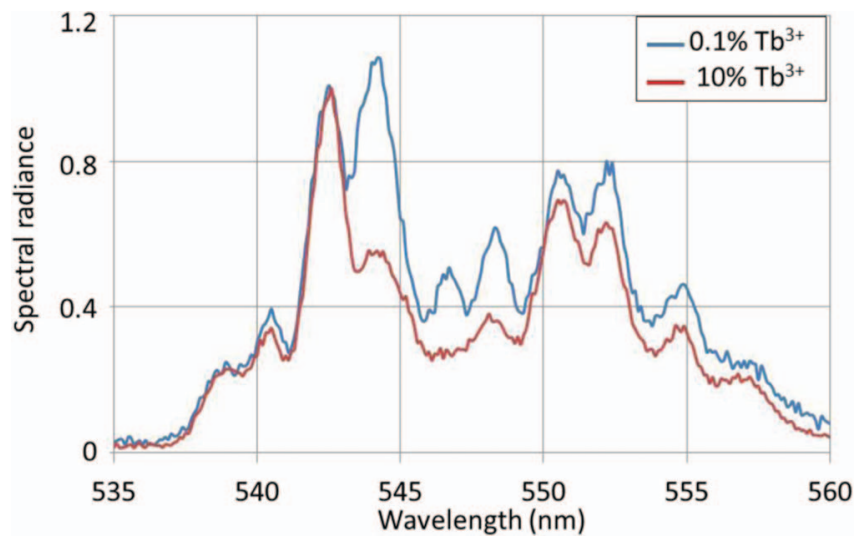

Figure 6. Normalized CL spectra of the ${ }^{5} \mathrm{D}_{4} \rightarrow{ }^{7} \mathrm{~F}_{5}$ transition cluster of nanosized $\mathrm{Y}_{2} \mathrm{O}_{3}: \mathrm{Tb}^{3+}$ with 0.1 and $10 \% \mathrm{~Tb}^{3+}$, recorded at $15 \mathrm{keV}$ and $5 \mu \mathrm{A} / \mathrm{cm}^{2}$. can be written as ${ }^{1}$ :

$$
D_{T b}=\sqrt[3]{\frac{100 M}{2 \rho N_{a v} c}},
$$

where $\mathrm{M}$ is the molecular weight of $\mathrm{Y}_{2} \mathrm{O}_{3}, \rho$ is the density of $\mathrm{Y}_{2} \mathrm{O}_{3}$, being $5.01 \mathrm{~g} / \mathrm{cm}^{3}$, and $\mathrm{N}_{\mathrm{av}}$ is Avogadro's number. The factor 100 appears in Eq. 4, because the concentration c is expressed in \%.

The correspondence between Figure 9, derived from the spectra recorded at low current density, and the equivalent Figure in our report on $\mathrm{Y}_{2} \mathrm{O}_{3}: \mathrm{Eu}^{3+}$ is striking; ${ }^{1}$ so, we conclude that the $542.8 \mathrm{~nm}$ peak refers to $\mathrm{Tb}^{3+}$ at a $\mathrm{C}_{2}$ site and the $544.4 \mathrm{~nm}$ peak refers to $\mathrm{Tb}^{3+}$ at

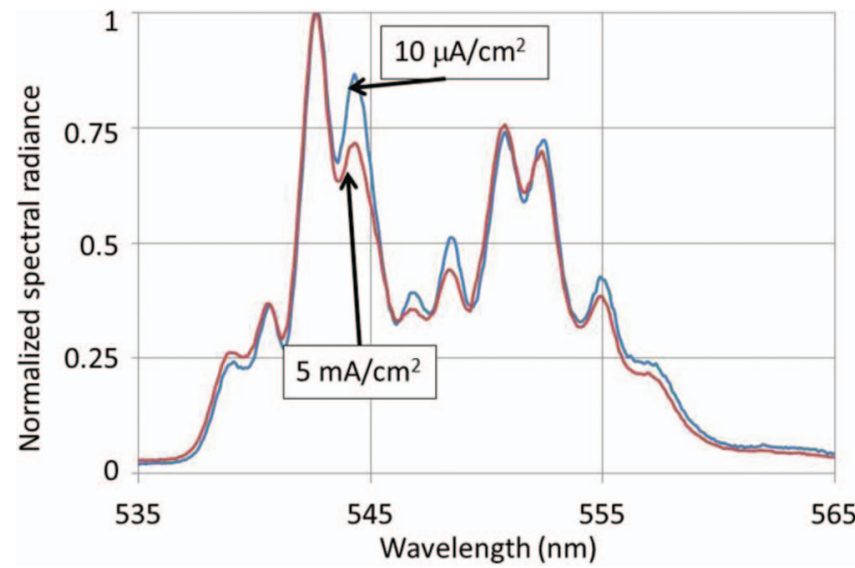

Figure 7. Normalized CL spectra of nanosized $\mathrm{Y}_{2} \mathrm{O}_{3}: \mathrm{Tb}^{3+}$ with $1 \% \mathrm{~Tb}^{3+}$ at $5 \mathrm{kV}$ of ${ }^{5} \mathrm{D}_{4} \rightarrow{ }^{7} \mathrm{~F}_{5}$ the transition cluster at low $\left(10 \mu \mathrm{A} / \mathrm{cm}^{2}\right)$ and high $\left(5 \mathrm{~mA} / \mathrm{cm}^{2}\right)$ current density. 


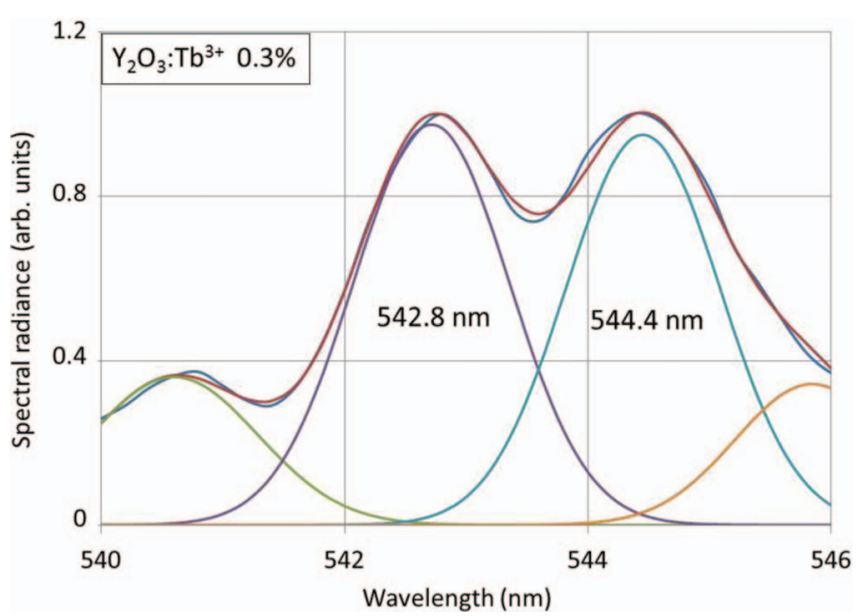

Figure 8. Deconvolution of a part of the ${ }^{5} \mathrm{D}_{4} \rightarrow{ }^{7} \mathrm{~F}_{5}$ spectrum between 540 and $546 \mathrm{~nm}$ with four Gaussian profiles.

an $\mathrm{S}_{6}$ site. The knee of the curve in Figure $9 \mathrm{~b}$ is at $1.7 \mathrm{~nm}$, which implies that the critical distance, $D_{T b^{3+}}^{C r i t}$, for interaction between the $\mathrm{S}_{6}$ and $\mathrm{C}_{2}$ sites is $1.7 \mathrm{~nm}$. This value is identical to the critical distance in $\mathrm{Y}_{2} \mathrm{O}_{3}: \mathrm{Eu}^{3+1}$. We have argued that $D_{T b^{3+}}^{C r i t}$ is two times larger than the distance $\mathrm{R}_{0}$, being the critical transfer distance for which the transfer rate of energy from $S_{6}$ to $C_{2}$ is equal to the radiative decay rate; ${ }^{24}$ consequently, $\mathrm{R}_{0}$ for $\mathrm{Y}_{2} \mathrm{O}_{3}: \mathrm{Tb}^{3+}$ is $0.85 \mathrm{~nm}$ and the same as $\mathrm{R}_{0}$ for $\mathrm{Y}_{2} \mathrm{O}_{3}: \mathrm{Eu}^{3+}$. Ozawa mentioned the change of the relative radiance of lines in the CL spectrum of $\mathrm{Y}_{2} \mathrm{O}_{3}: \mathrm{Tb}^{3+}$ upon varying the dopant concentration, ${ }^{2}$ but he did not specify which peaks were changing. Without splitting the ${ }^{5} \mathrm{D}_{4} \rightarrow{ }^{7} \mathrm{~F}_{5}$ transition into a doublet consisting of $\mathrm{a}_{2}$ and $\mathrm{S}_{6}$ part the concentration effects in the spectrum are modest, let alone that it would be possible to designate overlapping peaks in a low resolution spectrum.

Beside the high resolution spectra shown in Fig. 5 we have also recorded low resolution spectra at various e-beam voltages and a current density of $1 \mu \mathrm{A} / \mathrm{cm}^{2}$ with the Spectrobos 1200 spectroradiometers, which enable a direct evaluation of the color coordinate of the emitted light. This measurement was primarily carried out for the determination of the lumen efficiency, to be discussed in Luminous efficiency section; however, it allowed also a check on the possible reduction of $\mathrm{Tb}^{4+}$ ions in the $\mathrm{Y}_{2} \mathrm{O}_{3}$ lattice upon electron bombardment. Adjustment and measurement took about 2 minutes for each spectrum; the spectra were recorded in succession with spectrometer 2 at increasing e-beam voltages of 3, 6, 9, 12 and $15 \mathrm{kV}$. The color coordinates of the CL-spectra were constant, namely $\mathrm{x}=0.3280$ and $\mathrm{y}$ $=0.5750$ (CIE-1931). These color coordinates have not been checked via a calibration procedure of the spectrometers; however, for the present purpose the comparison is justified, because spectrometer and

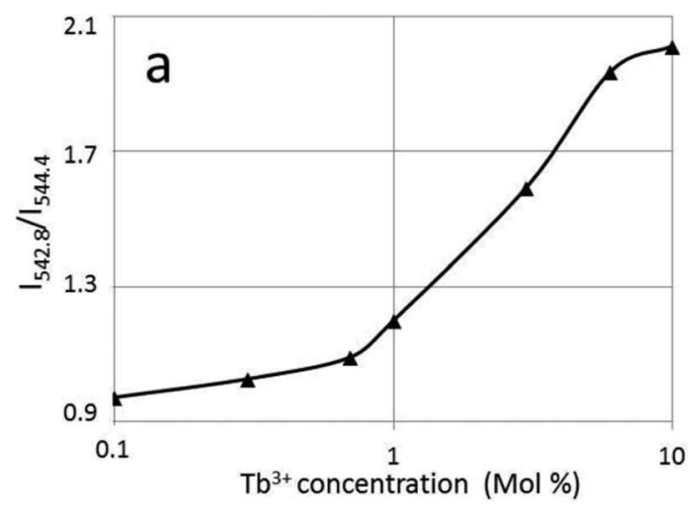

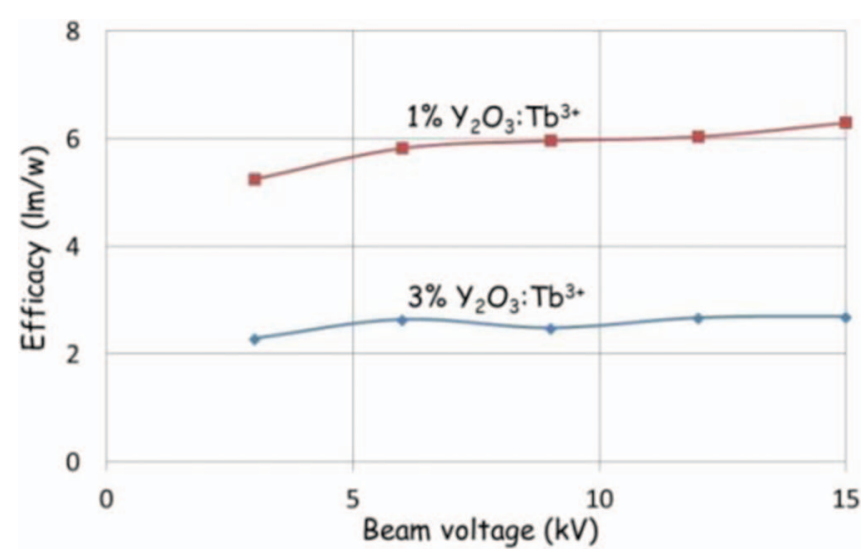

Figure 10. Lumen efficacy of nanosized $\mathrm{Y}_{2} \mathrm{O}_{3}: \mathrm{Tb}^{3+}$ versus beam voltage.

electron gun were not touched during the measurements. The invariance of the color coordinates versus time and beam voltage indicates that a possible reduction of a small quantity of $\mathrm{Tb}^{4+}$ ions to $\mathrm{Tb}^{3+}$ in the $\mathrm{Y}_{2} \mathrm{O}_{3}$ lattice upon electron bombardment can be neglected. There is another reason why we assume that a possible reduction of $\mathrm{Tb}^{4+}$ can be neglected in the present study, viz. the considerations on the ratio $\mathrm{I}_{542.8} / \mathrm{I}_{544.4}$, refer to wavelengths, which are so close, that an effect of a small change in the absorption due to a variation in the $\mathrm{Tb}^{4+}$ would have been detected in the deconvolutions discussed afore.

Luminous efficiency. - Thin layers of $\mathrm{Y}_{2} \mathrm{O}_{3}: \mathrm{Tb}^{3+}$ particles deposited on ITO coated glass slides were used for measuring the luminance and spectral radiance. The weight of the $\mathrm{Y}_{2} \mathrm{O}_{3}: \mathrm{Tb}^{3+}$ layers was $2 \mathrm{mg} / \mathrm{cm}^{2}$ for the $1 \% \mathrm{~Tb}^{3+}$ sample, yielding a layer thickness $6.2 \mu \mathrm{m} .{ }^{1}$ In the case of $3 \% \mathrm{~Tb}^{3+}$ the weight of the layer was less and the thickness was therefore smaller. The measurement method of the luminance and the evaluation of the luminous efficiency have been described extensively in our previous papers, ${ }^{1,19}$ hence, we may suffice in presenting the results only in Figure 10. The measurements were conducted in the $15 \mathrm{kV}$ rig at a current density of $1 \mu \mathrm{A} / \mathrm{cm}^{2}$. It can be seen that the luminous efficiency is almost constant between 6 and $15 \mathrm{kV}$. Since it was impossible to prepare layers of sufficient uniformity for the other $\mathrm{Tb}^{3+}$ concentrations, the optimum $\mathrm{Tb}^{3+}$ concentration could not be determined. Obviously, $\mathrm{Y}_{2} \mathrm{O}_{3}: \mathrm{Tb}^{3+}$ with $3 \%$ $\mathrm{Tb}^{3+}$ is already suffering from concentration quenching; so, the optimum concentration must be lower than $3 \%$.

The lumen efficacy of $\mathrm{Y}_{2} \mathrm{O}_{3}: \mathrm{Tb}^{3+}$ is smaller than that $\mathrm{Y}_{2} \mathrm{O}_{3}: \mathrm{Eu}^{3+1}$. This result is contrary to luminance data published by Cho et al. ${ }^{13}$

Decay.- Thin layers of nanosized $\mathrm{Y}_{2} \mathrm{O}_{3}: \mathrm{Tb}^{3+}$ particles on $\mathrm{C}$ substrates were excited with a partially focussed electron beam of $5 \mathrm{kV}$ rig and current densities between $100 \mu \mathrm{A} / \mathrm{cm}^{2}$ and $500 \mu \mathrm{A} / \mathrm{cm}^{2}$.

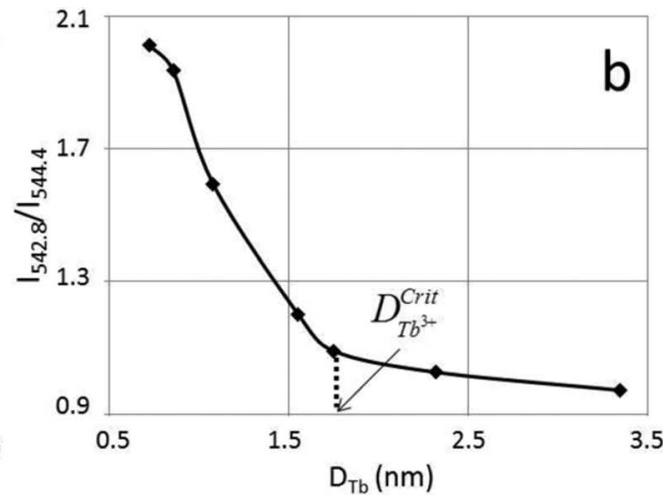

Figure 9. a. Plot of $\mathrm{I}_{542.8} / \mathrm{I}_{544.4}$ as a function of $\mathrm{Tb}^{3+}$ concentration. b. $\mathrm{I}_{542.8} / \mathrm{I}_{544.4}$ versus $\mathrm{D}_{\mathrm{Tb}}$. 


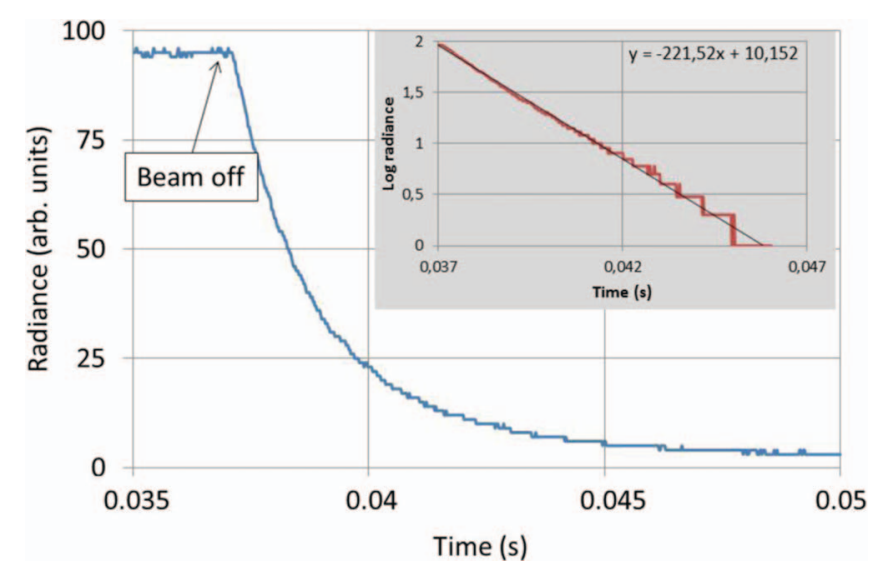

Figure 11. Decay of radiance of $542.8 \mathrm{~nm}$ peak of $\mathrm{Y}_{2} \mathrm{O}_{3}: \mathrm{Tb}^{3+}\left(0.3 \% \mathrm{~Tb}^{3+}\right)$; beam energy $5 \mathrm{keV}$, current density is $\approx 500 \mu \mathrm{A} / \mathrm{cm}^{2}$.

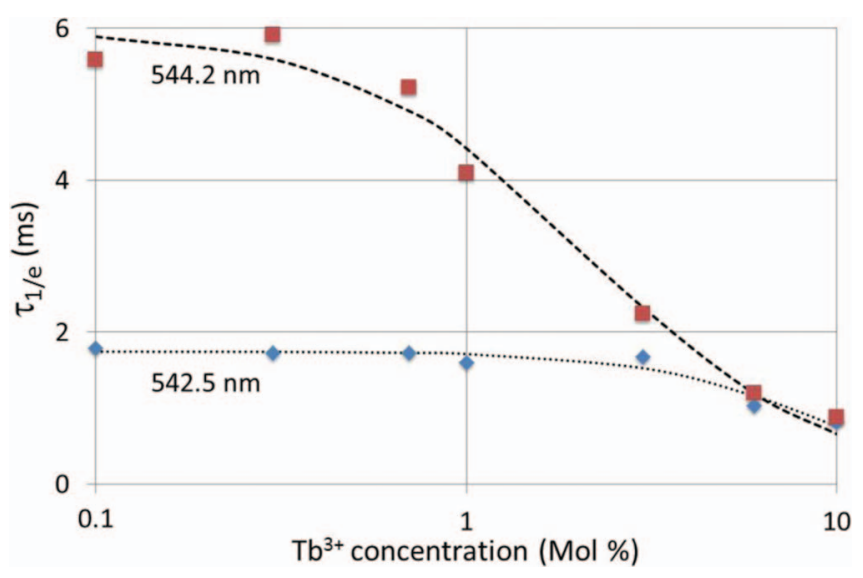

Figure 12. Decay times of $542.8 \mathrm{~nm}$ and $544.4 \mathrm{~nm}$ peaks of $\mathrm{Y}_{2} \mathrm{O}_{3}: \mathrm{Tb}^{3+}$ versus $\mathrm{Tb}^{3+}$ concentration. Points: experimental values, curves are fitted to the experimental results.

Some saturation of the $544.4 \mathrm{~nm}$ could occur at these conditions as can be seen in Figure 7. Since we did not observe differences upon lowering the current density to $10 \mu \mathrm{A} / \mathrm{cm}^{2}$ for this peak, we did not investigate this issue in more detail. The high resolution Bentham spectrometer was used to adjust the wavelength to be analyzed, which helped to minimize the interference from partially overlapping transitions. A typical decay curve for the ${ }^{5} \mathrm{D}_{4} \rightarrow{ }^{7} \mathrm{~F}_{5}\left(\mathrm{C}_{2}\right)$ transition at $542.8 \mathrm{~nm}$ is presented in Figure 11. These decay curves showed exponential behavior in most cases; decay times, $\tau_{1 / \mathrm{e}}$, were calculated from $\log$ plots as shown in Figure 11, including a small instrumental correction.

Figure 12 is a plot of the decay times $\left(\tau_{1 / \mathrm{e}}\right)$ as a function of the $\mathrm{Tb}^{3+}$ concentration in $\mathrm{Y}_{2} \mathrm{O}_{3}$.

The decay times of the experimental points represented in Figure 12 are also listed in Table I.

Table I. $\tau_{1 / \mathrm{e}}(\mathrm{ms})$ for $542.8 \mathrm{~nm}, 544.4 \mathrm{~nm}, 550.7 \mathrm{~nm}$ and $552.3 \mathrm{~nm}$ peaks of $\mathrm{Y}_{2} \mathrm{O}_{3}: \mathrm{Tb}^{3+}$.

Conc. $\mathrm{Tb}^{3+}(\mathrm{Mol} \%) \quad \mathrm{C}_{2} 542.8 \mathrm{~nm} \quad \mathrm{~S}_{6} 544.4 \mathrm{~nm} \quad 550.7 \mathrm{~nm} \quad 552.3 \mathrm{~nm}$

\begin{tabular}{ccccc}
\hline 0.1 & 1.8 & 5.6 & 2.0 & 2.7 \\
0.3 & 1.7 & 5.2 & 2.1 & 2.6 \\
0.7 & 1.7 & 5.8 & 2.0 & 2.3 \\
1 & 1.6 & 4.1 & & \\
3 & 1.7 & 2.2 & & \\
6 & 1.0 & 1.2 & & \\
10 & 0.8 & 0.9 & &
\end{tabular}

Table II. Parameters for decay curves represented in Figure 11.

\begin{tabular}{ccc} 
Parameter & $542.8 \mathrm{~nm}\left(\mathrm{C}_{2}\right)$ & $544.4 \mathrm{~nm}\left(\mathrm{~S}_{6}\right)$ \\
\hline$\tau_{\mathrm{r}}(\mathrm{ms})$ & 1.74 & 5.98 \\
$\mathrm{~A}$ & 0.020 & 0.353 \\
$\gamma$ & 1.83 & 1.36
\end{tabular}

The experimental results for $542.8 \mathrm{~nm}$ and $544.4 \mathrm{~nm}$ peaks shown in Fig. 12 were fitted to curves, which can be written as: ${ }^{1,18}$

$$
\tau_{1 / e}=\frac{\tau_{r}}{1+A \tau_{r} c^{\gamma}},
$$

where $\tau_{\mathrm{r}}$ is the radiative decay time (in $\mathrm{ms}$ ) and the second term in the denominator representing the radiationless decay, in which $\mathrm{c}$ is the concentration of $\mathrm{Tb}^{3+}$ in $\%$ and $\mathrm{A}$ and $\gamma$ are parameters that were fitted to the measured time constants. The parameters that were obtained by a least squares fit are listed in Table II.

The results presented in Figure 12 and Tables I and II indicate that the radiative decay time of the $544.4 \mathrm{~nm}$ peak is 3.4 times longer than that for the $542.8 \mathrm{~nm}$ peak (at low $\mathrm{Tb}^{3+}$ concentrations). This is what one might expect if the $544.4 \mathrm{~nm}$ peak refers to $\mathrm{Tb}^{3+}$ at an $\mathrm{S}_{6}$ site and the $542.8 \mathrm{~nm}$ peak refers to $\mathrm{Tb}^{3+}$ at a $\mathrm{C}_{2}$ site. The $\mathrm{S}_{6}$ site has inversion symmetry, which forbids direct electric dipole transitions, but magnetic dipole transitions are possible for this symmetry, which yield usually longer decay times. We conclude therefore that the decay measurements support the assignment of the $542.8 \mathrm{~nm}$ and $544.4 \mathrm{~nm}$ peaks to ${ }^{5} \mathrm{D}_{4} \rightarrow{ }^{7} \mathrm{~F}_{5}\left(\mathrm{C}_{2}\right)$ and ${ }^{5} \mathrm{D}_{4} \rightarrow{ }^{7} \mathrm{~F}_{5}\left(\mathrm{~S}_{6}\right)$ transitions respectively.

Table I also lists decay times for the other two strong peaks in the ${ }^{5} \mathrm{D}_{4} \rightarrow{ }^{7} \mathrm{~F}_{5}$ transition cluster of $\mathrm{Y}_{2} \mathrm{O}_{3}: \mathrm{Tb}^{3+}$, viz. the doublet at $550.7 \mathrm{~nm}$ and $552.3 \mathrm{~nm}$. The decay times are between the values obtained for the peaks at $542.8 \mathrm{~nm}$ and $544.4 \mathrm{~nm}$, indicating that the first mentioned doublet is a mixture of $\mathrm{C}_{2}$ and $\mathrm{S}_{6}$ type transitions. This is also confirmed in Figure 5a, showing that the concentration effect is stronger for the $552.3 \mathrm{~nm}$ peak than that for the $550.7 \mathrm{~nm}$ peak. So, the $\mathrm{S}_{6}$-content in the $552.3 \mathrm{~nm}$ peak is higher and thus leads to a somewhat longer decay time.

Analysis with STEM.- As mentioned in the Experimental section, the TEM in our laboratory has the possibility to record panchromatic images as represented in Figure $3 \mathrm{~d}$ and to measure CL spectra. These spectra can be recorded at temperatures from $102 \mathrm{~K}$ to $303 \mathrm{~K}$. Figure 13 shows the CL spectra of $3 \% \mathrm{Y}_{2} \mathrm{O}_{3}: \mathrm{Tb}^{3+}$ at $102 \mathrm{~K}$ and 303 $\mathrm{K}$ recorded at $200 \mathrm{keV}$.

Figure 13 indicates that the spectrum at $102 \mathrm{~K}$ has sharper peaks because of less vibronic broadening; moreover, the ratio $\mathrm{I}_{542.8} / \mathrm{I}_{544.4}$

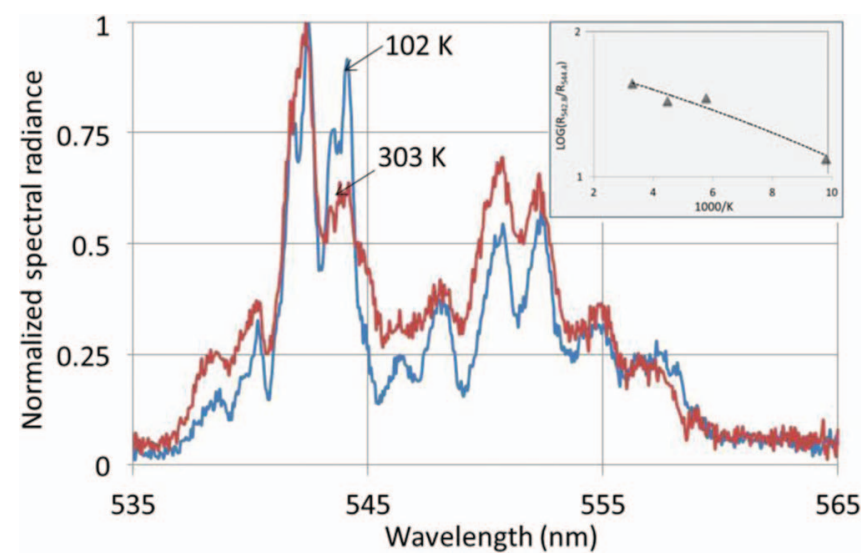

Figure 13. CL spectra of $3 \% \mathrm{Y}_{2} \mathrm{O}_{3}: \mathrm{Tb}^{3+}$ at $102 \mathrm{~K}$ and $303 \mathrm{~K}$ in TEM. Spectra have been normalized to unity at $542.8 \mathrm{~nm}$. For reasons of clarity, spectra at $173 \mathrm{~K}$ and $223 \mathrm{~K}$ with intermediate radiance values have been omitted: the peak values of the $544.4 \mathrm{~nm}$ line were between those of $102 \mathrm{~K}$ and $303 \mathrm{~K}$. The inset is a plot of $\mathrm{LOG}\left(\mathrm{I}_{542.8} / \mathrm{I}_{544.4}\right)$ versus $1000 / \mathrm{K}$. 


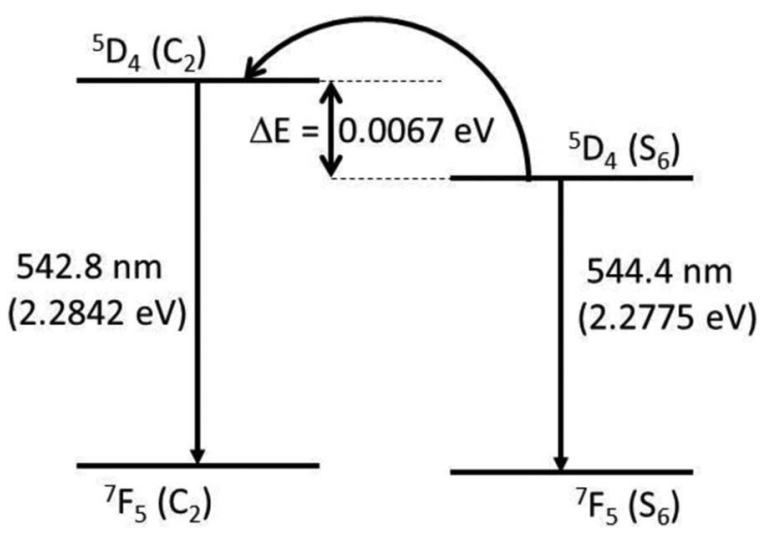

Figure 14. Mechanism of electron transfer from ${ }^{5} \mathrm{D}_{4}\left(\mathrm{~S}_{6}\right)$ to ${ }^{5} \mathrm{D}_{4}\left(\mathrm{C}_{2}\right)$; energy levels are not on scale for reasons of clarity.

increases with temperature. This phenomenon indicates that the electron transfer from $\mathrm{Tb}^{3+}$ at $\mathrm{S}_{6}$ to $\mathrm{Tb}^{3+}$ at $\mathrm{C}_{2}$ is much less at low temperature than at room temperature. Another interesting feature of Figure 13 is the increase of the spectral radiance between $545 \mathrm{~nm}$ and $552 \mathrm{~nm}$ with temperature. This may also be attributed to vibronic broadening and thus, it is another indication that detection of the many hidden lines in the ${ }^{5} \mathrm{D}_{4} \rightarrow{ }^{7} \mathrm{~F}_{4}$ transition cluster will be impossible without further lowering of the temperature. Finally, the low temperature spectrum in Figure 13 indicates that the peaks at $542.8 \mathrm{~nm}$ and 544.4 $\mathrm{nm}$ are doublets. This feature has not been analyzed in the present study. Since our equipment does not enable lower temperatures than $102 \mathrm{~K}$, we are currently trying to improve the signal to noise ratio. Results of this study will be published as soon as they have been completed.

The inset of Figure 13 is an Arrhenius plot of the ratio $\mathrm{I}_{542.8} / \mathrm{I}_{544.4}$, in which $\operatorname{LOG}\left(\mathrm{I}_{542.8} / \mathrm{I}_{544.4}\right)$ is plotted against $1000 / \mathrm{K}$. Such an analysis is obvious, because the ratio $\mathrm{I}_{542.8} / \mathrm{I}_{544.4}$ refers to the rate of populating and depopulating energy levels. The activation energy calculated from this plot is $0.005 \mathrm{eV}$. The accuracy of this value is not particularly high, but the order of magnitude is equal to the energy difference between the $542.8 \mathrm{~nm}$ and 544.4 peaks, shown in Figure 14, which visualizes the mechanism of the above mentioned electron transfer from the $\mathrm{S}_{6}$ to $\mathrm{C}_{2} \mathrm{~Tb}^{3+}$ ion.

The energy difference between the ${ }^{5} \mathrm{D}_{4}\left(\mathrm{~S}_{6}\right)$ and ${ }^{5} \mathrm{D}_{4}\left(\mathrm{C}_{2}\right)$ levels, being $0.0067 \mathrm{eV}$, has been calculated from the wavelengths of the indicated spectral transitions. When the temperature of the crystal is $78 \mathrm{~K}$, the energy gap of $0.0067 \mathrm{eV}$ can be bridged and electrons can be promoted via phonon assistance from the ${ }^{5} \mathrm{D}_{4}\left(\mathrm{~S}_{6}\right)$ to the ${ }^{5} \mathrm{D}_{4}\left(\mathrm{C}_{2}\right)$ level. The higher the temperature the more electrons will be promoted. This mechanism explains the change of the spectra with temperature in Figure 13. The low temperature spectrum in Figure 13 was recorded at $102 \mathrm{~K}$, which is slightly higher than the theoretical onset of $78 \mathrm{~K}$. In other words, it is to be expected that at $102 \mathrm{~K}$ already a few electron have been promoted. This may also be concluded from Figures 6 and 9 , because for a concentration of $0.1 \% \mathrm{~Tb}^{3+}$ electron transfer from $\mathrm{Tb}^{3+}$ $\left(\mathrm{S}_{6}\right)$ to $\mathrm{Tb}^{3+}\left(\mathrm{C}_{2}\right)$ is virtually impossible. At that condition $\mathrm{I}_{542.8} / \mathrm{I}_{544.4}$ would be 0.97 , whereas Figure 13 already indicates a larger value of about 1.1 for this ratio.

Decay analysis with FESEM.- Figure 15 is a CL-image of nanosized $\mathrm{Y}_{2} \mathrm{O}_{3}: \mathrm{Tb}^{3+}$ particles on a $\mathrm{C}$-substrate. The smearing of the image is due to the rather long decay time of the $\mathrm{Tb}^{3+}$ ions. The CL-detector only enables the recording of panchromatic images, which implies that the decay times evaluated with the FESEM are "overall" decay times.

The bright comets in Figure 15 refer to small clusters of nano particles while the faint comets are from individual particles as shown in Figure $3 \mathrm{a}$. For $\mathrm{Tb}^{3+}$ concentrations $>0.3 \%$ the gray scale in the tail of a comet varied exponentially. In the case of low $\mathrm{Tb}^{3+}$ concentrations

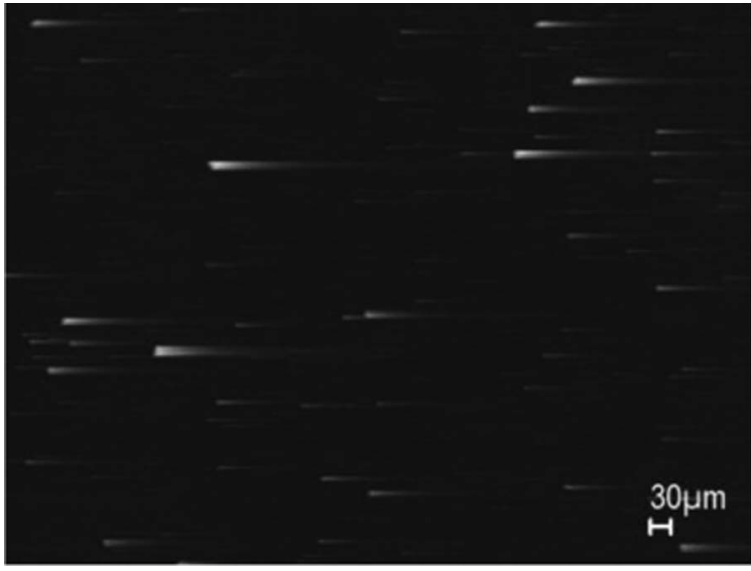

Figure 15. CL image of $1 \% \mathrm{Y}_{2} \mathrm{O}_{3}: \mathrm{Tb}^{3+}$ recorded in FESEM at $10 \mathrm{kV}$. The scan speed of this image was $20.2 \mathrm{~s} /$ frame.

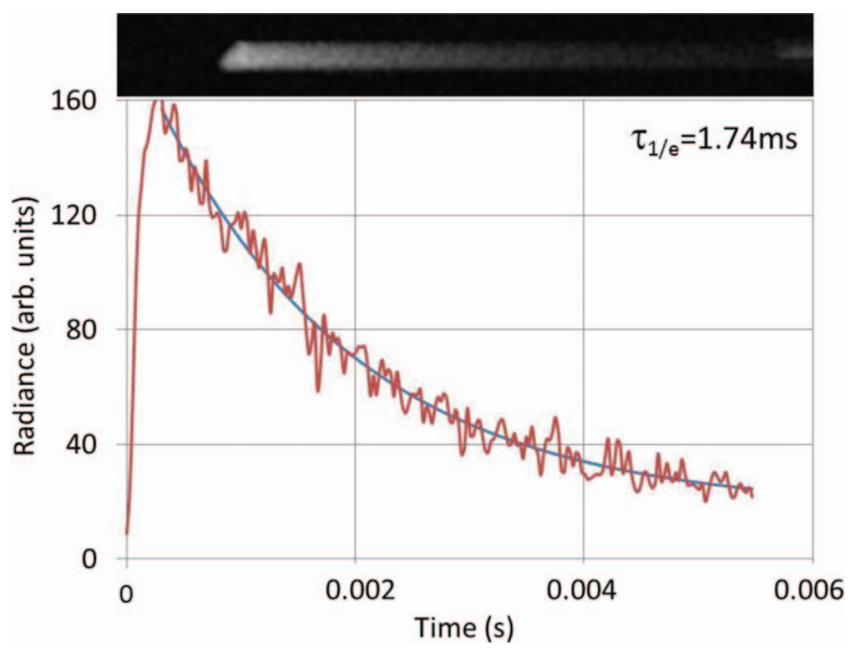

Figure 16. Brightness decay of small cluster of $\mathrm{Y}_{2} \mathrm{O}_{3}: \mathrm{Tb}^{3+}$ particles with $0.7 \% \mathrm{~Tb}^{3+}$; CL-image on top. Beam voltage of FESEM $10 \mathrm{kV}$.

deviations were observed, which are caused by different degrees of saturation of excited levels. This has been explained in our previous reports. ${ }^{1,23}$ By using the Image $\mathbf{J}$ software the overall decay times of the FESEM images were determined. An example is shown in Figure 16.

Curve fitting to a one-exponential function was done with a least squares algorithm, in which the background brightness was accounted for. Results for the various concentration of $\mathrm{Tb}^{3+}$ are summarized in Table III.

In the case of $\mathrm{Y}_{2} \mathrm{O}_{3}: \mathrm{Tb}^{3+}$ with $0.1 \% \mathrm{~Tb}^{3+}$ the saturation was particularly strong. For this $\mathrm{Tb}^{3+}$ concentration the light distribution in the comets could be represented by two exponentials with

\begin{tabular}{lc}
\hline $\begin{array}{l}\text { Table III. Decay times of } \mathbf{Y}_{2} \mathbf{O}_{3}: \mathbf{T b}^{3+} \text { particles evaluated form } \\
\text { CL-images recorded with FESEM. }\end{array}$ \\
\begin{tabular}{cc} 
Conc. $\mathrm{Tb}^{3+}(\mathrm{Mol} \%)$ & $\tau_{1 / \mathrm{e}}(\mathrm{ms})$ \\
\hline 0.1 & $0.13 \& 1.8^{*}$ \\
0.3 & 1.7 \\
0.7 & 1.8 \\
1 & 1.7 \\
3 & 1.7
\end{tabular}
\end{tabular}

${ }^{*}$ Comets were represented by two exponentials. 


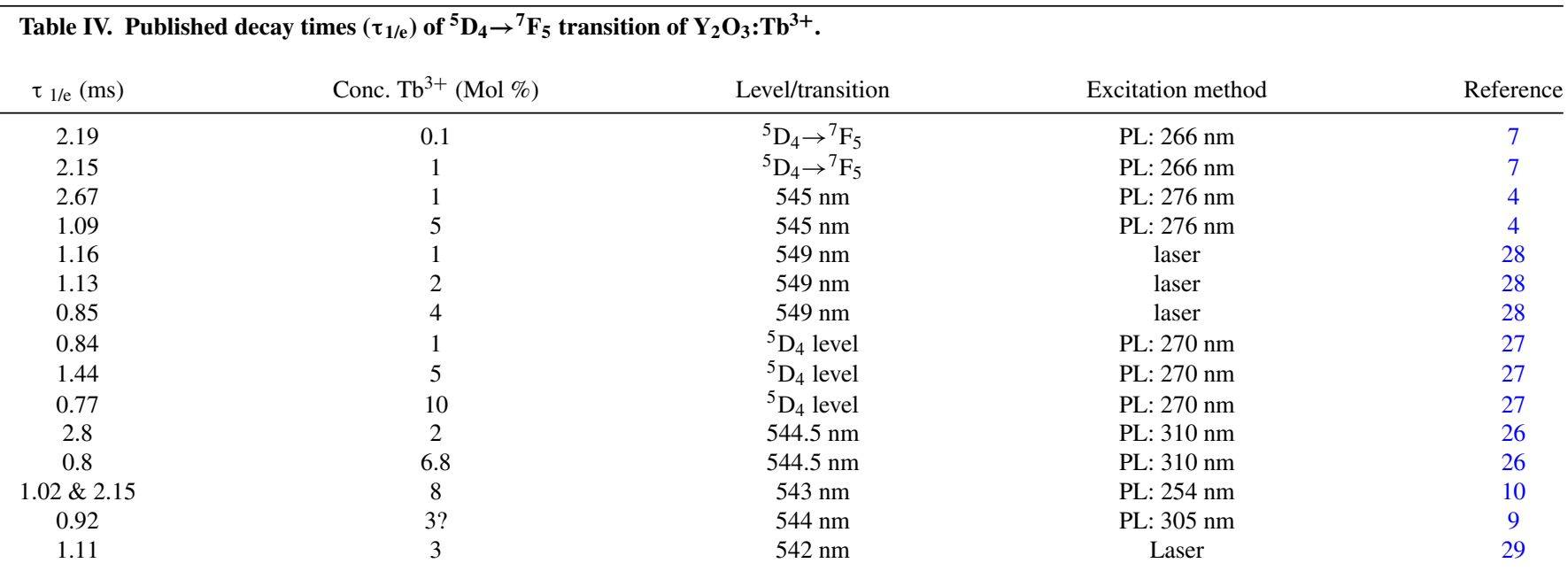

decay times as indicated in Table III. The "overall" decay times in Table III determined from the FESEM-images match with the decay times determined for the ${ }^{5} \mathrm{D}_{4} \rightarrow{ }^{7} \mathrm{~F}_{5}\left(\mathrm{C}_{2}\right)$ at $542.8 \mathrm{~nm}$, listed in Table I. In other words, the contribution of the $\mathrm{S}_{6}$ transitions with longer persistence can be neglected in the CL-images, because of the stronger saturation of the ${ }^{5} \mathrm{D}_{4}\left(\mathrm{~S}_{6}\right)$ level(s) in $\mathrm{Y}_{2} \mathrm{O}_{3}: \mathrm{Tb}^{3+}$. We shall discuss this issue in more detail in the next section.

\section{Discussion}

In CL spectrum section we have already noticed that the variation of the $\mathrm{Tb}^{3+}$ concentration is clearly observable in the ${ }^{5} \mathrm{D}_{4} \rightarrow{ }^{7} \mathrm{~F}_{5}$ (Figure 5a) and ${ }^{5} \mathrm{D}_{4} \rightarrow{ }^{7} \mathrm{~F}_{3}$ (Figure $5 \mathrm{c}$ ) transition clusters, but hardly in the ${ }^{5} \mathrm{D}_{4} \rightarrow{ }^{7} \mathrm{~F}_{4}$ (Figure 5d) and ${ }^{5} \mathrm{D}_{4} \rightarrow{ }^{7} \mathrm{~F}_{6}$ (Figure $5 \mathrm{~b}$ ) clusters. For the first two transition clusters $\Delta \mathrm{J}=+1$ and $\Delta \mathrm{J}=-1$ respectively, whereas $\Delta \mathrm{J}=0$ for ${ }^{5} \mathrm{D}_{4} \rightarrow{ }^{7} \mathrm{~F}_{4}$ and $\Delta \mathrm{J}=+2$ for ${ }^{5} \mathrm{D}_{4} \rightarrow{ }^{7} \mathrm{~F}_{6}$. The latter transition cluster is a so-called forced electric-dipole transition, which is magnetically forbidden. ${ }^{3}$ A small concentration effect is noticeable for the peak at $583.2 \mathrm{~nm}$ in the ${ }^{5} \mathrm{D}_{4} \rightarrow{ }^{7} \mathrm{~F}_{4}$ transition cluster (Figure $5 \mathrm{~d}$ ). When $\mathrm{Tb}^{3+}$ is at an $\mathrm{S}_{6}$ site it may display magnetic dipole transitions with $\Delta \mathrm{J}=0, \pm 1$. So, it can be concluded that assigning the $544.4 \mathrm{~nm}$ peak in the ${ }^{5} \mathrm{D}_{4} \rightarrow{ }^{7} \mathrm{~F}_{5}$ cluster and the $630.1 \mathrm{~nm}$ and $637.8 \mathrm{~nm}$ peaks in the ${ }^{5} \mathrm{D}_{4} \rightarrow{ }^{7} \mathrm{~F}_{3}$ transitions cluster as $\mathrm{S}_{6}$ transitions and the virtual absence of $\mathrm{S}_{6}$ transitions in the ${ }^{5} \mathrm{D}_{4} \rightarrow{ }^{7} \mathrm{~F}_{6}$ transition cluster are in line with the selection rules. The $547.0 \mathrm{~nm}$ and $548.6 \mathrm{~nm}$ peaks in the ${ }^{5} \mathrm{D}_{4} \rightarrow{ }^{7} \mathrm{~F}_{5}$ transition cluster (Figure 5a and Figure 6) may also be assigned as $\mathrm{S}_{6}$ transitions. Due to substantial overlapping of neighboring peaks, we did not investigate these peaks in detail. Figure 13 shows a pronounced sharpening of these peaks by lowering the temperature to $102 \mathrm{~K}$. As mentioned in Decay section the longer $\tau_{1 / \mathrm{e}}$ decay time for the $\mathrm{S}_{6}$ transition at $544.4 \mathrm{~nm}$ as compared to the $\mathrm{C}_{2}$ transition at 542.8 $\mathrm{nm}$ is in line with what may be expected from magnetic- and electricdipole transitions respectively. Further support for the above assignment can be deduced from Figure 7, which shows a stronger saturation effect for the $544.4 \mathrm{~nm}$ peak than that for the $542.8 \mathrm{~nm}$ peak. From our findings, which are summarized in Figure 14, it can be concluded that the phonon assisted transition from ${ }^{5} \mathrm{D}_{4}\left(\mathrm{~S}_{6}\right)$ to ${ }^{5} \mathrm{D}_{4}\left(\mathrm{C}_{2}\right)$ is symmetryallowed, whereas the reverse route, which is energetically favorable and does not need phonon assistance, is symmetry-forbidden.

We mentioned in the introduction section that because of the equivalence of ion radii between $\mathrm{Y}^{3+}$ and $\mathrm{Tb}^{3+}$ it is obvious to assume that there are three times less $\mathrm{Tb}^{3+}$ ions at $\mathrm{S}_{6}$ than at $\mathrm{C}_{2}$ sites in the $\mathrm{Y}_{2} \mathrm{O}_{3}$ lattice. The saturation effect at continuous irradiance with an electron beam having a current density $\mathrm{j}$ can be estimated by using a simple equation that has been derived by Bril and Kröger ${ }^{25}$ :

$$
R_{i}=\frac{j \eta_{i}}{1+j \eta_{i} \tau_{i} / N_{i}}
$$

where $\mathrm{R}_{\mathrm{i}}$ is the radiance of transition $\mathrm{i}\left(={ }^{5} \mathrm{D}_{4} \rightarrow{ }^{7} \mathrm{~F}_{5}\left(\mathrm{C}_{2}\right)\right.$ or ${ }^{5} \mathrm{D}_{4} \rightarrow{ }^{7} \mathrm{~F}_{5}$ $\left.\left(\mathrm{S}_{6}\right)\right), \eta_{\mathrm{i}}$ is the efficiency of transition $\mathrm{i}$ at low current density and $\mathrm{N}_{\mathrm{i}}$ is the number of $\mathrm{Tb}^{3+}$ ions per $\mathrm{cm}^{3}$ at $\mathrm{C}_{2}$ or $\mathrm{S}_{6}$. If $\eta_{\mathrm{C} 2} \approx \eta_{\mathrm{S} 6}$ and because $\mathrm{N}_{\mathrm{C} 2}=3 \mathrm{~N}_{\mathrm{S} 6}$ and moreover $\tau_{\mathrm{C} 2}<\tau_{\mathrm{S} 6}$, then it is clear from $\mathrm{Eq}$. 6 that the effect of saturation by increasing $\mathrm{j}$ is more pronounced for the $S_{6}$ transition. This consideration also explains that the CL images of the FESEM, in which effective current densities of about $1 \mathrm{~A} / \mathrm{cm}^{2}$ are rife, ${ }^{1}$ lack longer persistence $\mathrm{S}_{6}$-light.

In spite of the extensive literature on the luminescence of $\mathrm{Y}_{2} \mathrm{O}_{3}: \mathrm{Tb}^{3+}$, it is not easy to make a comparison between the results of this work and those of other authors. An important reason is the resolution of the spectrometer. The published spectra of bulk and nanosized $\mathrm{Y}_{2} \mathrm{O}_{3}: \mathrm{Tb}^{3+}$ show usually only two peaks for the various ${ }^{5} \mathrm{D}_{4} \rightarrow{ }^{7} \mathrm{~F}_{\mathrm{J}}$ transition clusters. ${ }^{4-10,12-14,26,27}$ As can be seen in Figure 5a for the ${ }^{5} \mathrm{D}_{4} \rightarrow{ }^{7} \mathrm{~F}_{5}$ cluster, these two peaks must be (1) a fusion between the $542.8 \mathrm{~nm}$ and $544.4 \mathrm{~nm}$ peaks, being named here "peak A", in the literature sometimes indicated by wavelength $(543 \mathrm{~nm}, 544 \mathrm{~nm}$, $545 \mathrm{~nm}$ or even $549 \mathrm{~nm}$ ) or as the ${ }^{5} \mathrm{D}_{4} \rightarrow{ }^{7} \mathrm{~F}_{5}$ transition, and (2) a fusion of the peaks at $551.0 \mathrm{~nm}$ and $552.6 \mathrm{~nm}$, being named "peak B". The ratio of the maximum radiance $(\mathrm{A} / \mathrm{B})$ of these fused peaks is found to be 1.2-1.4 in the literature. The same ratio is found by us after the fusing procedure: this ratio decreases slightly upon increasing the $\mathrm{Tb}^{3+}$ concentration. The fusion peak $\mathrm{A}$ is thus a mixture of the $\mathrm{C}_{2}$ and $\mathrm{S}_{4}$ transitions. Figure $5 \mathrm{a}$ and Table I indicate that there is also $\mathrm{S}_{6}$ content in the fusion peak B.

Table IV summarizes decay times of the ${ }^{5} \mathrm{D}_{4} \rightarrow{ }^{7} \mathrm{~F}_{5}$ transition of $\mathrm{Y}_{2} \mathrm{O}_{3}: \mathrm{Tb}^{3+}$ published by other authors.

The data listed in Table IV show that $\tau_{1 / \mathrm{e}}$ decreases when the $\mathrm{Tb}^{3+}$ concentration is increased and that there are substantial deviations between the various authors. The decrease of the decay time at larger concentration is also shown in Figure 12: for the $544.4 \mathrm{~nm}$ peak more pronounced than for the $542.8 \mathrm{~nm}$ peak. The decay data of Table IV do not refer to the $542.8 \mathrm{~nm}$ or $544.4 \mathrm{~nm}$ peaks of Fig. $5 \mathrm{a}$, but rather to the fusion peak A, defined above. The data can therefore not be compared directly to our results as summarized in Table I, but indirectly it is possible. From Figure 9a it can be derived that $\mathrm{I}_{542.8} / \mathrm{I}_{544.4}$ is 1.6 for $3 \%$ $\mathrm{Y}_{2} \mathrm{O}_{3}: \mathrm{Tb}^{3+}$, which implies that when the peaks are fused together, the $\mathrm{C}_{2}$ content is 1.6 times larger than the $\mathrm{S}_{6}$ content. For $3 \% \mathrm{Y}_{2} \mathrm{O}_{3}: \mathrm{Tb}^{3+}$ the overall decay time of this fusion peak would be $1.8 \mathrm{~ms}$, which agrees quite well with the data in Table IV.

\section{Conclusions}

Recording the CL spectra of nanosized cubic $\mathrm{Y}_{2} \mathrm{O}_{3}: \mathrm{Tb}^{3+}$ with a high resolution spectrometer enabled the identification of peaks that are related to $\mathrm{Tb}^{3+}$ at $\mathrm{C}_{2}$ and $\mathrm{S}_{6}$ sites in the $\mathrm{Y}_{2} \mathrm{O}_{3}$ crystal. From our literature search we could not find that others have assigned this previously. The critical distance for energy transfer from $\mathrm{Tb}^{3+}$ ions 
at $\mathrm{S}_{6}$ lattice sites to $\mathrm{Tb}^{3+}$ ions at $\mathrm{C}_{2}$ lattice sites, $D_{T b^{3+}}^{C r i t}$, was found to be $1.7 \mathrm{~nm}$. This distance is identical to that in $\mathrm{Y}_{2} \mathrm{O}_{3}: \mathrm{Eu}^{3+}$, which is not unexpected, because $\mathrm{Eu}^{3+}$ and $\mathrm{Tb}^{3+}$ have the same ion size and corresponding $4 \mathrm{f}-4 \mathrm{f}$ and $4 \mathrm{f}-5 \mathrm{~d}\left(\mathrm{in} \mathrm{Tb}^{3+}\right.$ ) relaxations. At a temperature $<78 \mathrm{~K}$ the phonon assisted transfer of energy from ${ }^{5} \mathrm{D}_{4}\left(\mathrm{~S}_{6}\right)$ to ${ }^{5} \mathrm{D}_{4}$ $\left(\mathrm{C}_{2}\right)$ stops in $\mathrm{Y}_{2} \mathrm{O}_{3}: \mathrm{Tb}^{3+}$ with a high concentration of $\mathrm{Tb}^{3+}$; when the temperature is $>78 \mathrm{~K}$, this transfer is enabled due to phonon assistance.

The decay times of the ${ }^{5} \mathrm{D}_{4} \rightarrow{ }^{7} \mathrm{~F}_{5}\left(\mathrm{C}_{2}\right)$ and the ${ }^{5} \mathrm{D}_{4} \rightarrow{ }^{7} \mathrm{~F}_{5}\left(\mathrm{~S}_{6}\right)$ transitions decrease at high $\mathrm{Tb}^{3+}$ concentration; this effect starts for $\mathrm{S}_{6}$ at lower concentrations than for $\mathrm{C}_{2}$. Decay times determined with the FESEM at very high current density of about $1 \mathrm{~A} / \mathrm{cm}^{2}$ are equal to the decay times of the ${ }^{5} \mathrm{D}_{4} \rightarrow{ }^{7} \mathrm{~F}_{5} \mathrm{C}_{2}$ transition determined at a current density of about $0.5 \mathrm{~mA} / \mathrm{cm}^{2}$. The contribution of longer persistence $\mathrm{S}_{6}$ transitions to CL-images in the FESEM is minimized because of the strong saturation of these transitions.

Finally, we would like to stress that the conclusions obtained from this study are of a preliminary character and need to be updated with more detailed studies at low temperature, i.e. is the splitting of the lines at $542.8 \mathrm{~nm}$ and $544.4 \mathrm{~nm}$ at low temperature shown in Figure 13 real? Currently we are studying the PL and CL from nanosized $\mathrm{Y}_{2} \mathrm{O}_{3}: \mathrm{Tb}^{3+}$ particles at room temperature and low temperature to answer this question and to get a better insight into the transfer of energy after excitation of the lattice (CL) or target levels (PL) in this phosphor.

\section{Acknowledgments}

We are grateful to the EPSRC and the Technology Strategy Board (TSB) for funding the PURPOSE (TP11/MFE/6/I/AA129F; EPSRC TS/G000271/1) and CONVERTED (JeS no. TS/1003053/1) programs. We are also grateful to the TSB for funding the CONVERT program.

\section{References}

1. D. den Engelsen, P. G. Harris, T. G. Ireland, and J. Silver, ECS J. Solid State Sci. Technol., 4, R1 (2015)

2. L. Ozawa, Cathodoluminescence, Theory and Applications, p. 165 , Kodansha \& VCH Verlag, Tokyo (1990).
3. G. Blasse and B. C. Grabmaier, Luminescent Materials, p. 44, Springer-Verlag, Berlin (1994).

4. G. A. Sotiriou, M. Schneider, and S. E. Pratsini, J. Phys. Chem. C, 116, 4493 (2012)

5. W. C. Chien, Y. Y. Yu, and C. C. Yang, Mater. Design, 31, 1737 (2010).

6. S. Som, S. Dutta, Vijay Kumar, Vinod Kumar, H. C. Swart, and S. K. Sharma, J. Lumin., 146, 162 (2014).

7. Q. Meng, B. Chen, W. Xu, Y. Yang, X. Zhao, W. Di, S. Lu, X. Wang, J. Sun, L. Cheng, T. Yu, and Y. Peng, J. Appl. Phys., 102, 093505 (2007).

8. Z. Liu, L. Yu, Q. Wang, Y. Tao, and H. Yang, J. Lumin., 131, 12 (2011)

9. H. Jiu, Y. Fu, L. Zhang, Y. Sun, Y. Wang, and T. Han, Micro Nano Lett., 7, 947 (2012).

10. J. H. Park, N. G. Back, M. G. Kwak, B. E. Jun, B. C. Choi, B. K. Moon, J. H. Jeong, S. S. Yi, and J. B. Kim, Mater. Sci. Eng. C, 27, 998 (2007).

11. J. Heber, K. H. Hellwege, U. Köbler, H. Murmann, and Z. Physik, 237, 189 (1970).

12. G. Alarcón-Flores, M. García-Hipólito, M. Aguilar-Frutis, S. Carmona-Téllez, R. Martinez-Martinez, M. P. Campos-Arias, M. Jiménez-Estrada, and C. Falcon, ECS J. Solid State Sci. Technol., 3, R189 (2014).

13. J. Y. Cho, Y. D Huh, C. R. Park, and Y. R. Do, J. Electrochem Soc., 154, J272 (2007).

14. C. D. Cress, C. S. Redino, B. J. Landi, and R. P. Raffaelle, J. Solid State Chem., 181, 2041 (2008)

15. R. Withnall, M. I. Martinez-Rubio, G. R Fern, T. G. Ireland, and J. Silver, J. Opt. A: Pure Appl. Opt., 5, S81 (2003).

16. E. T. Goldburt, B. Kulkami, R. N. Bhargava, J. Taylor, and M. Libera, J. Lumin., 72-74, 190 (1997).

17. T. Kano in Phosphor Handbook, 2nd ed., W. Yen, S. Shionoya, and H. Yamamoto eds., p. 199 \& 208, CRC Press, Boca Raton (2007).

18. D. B. M. Klaassen, R. A. M. van Ham, and T. G. M. van Rijn, J. Lumin., 43, 261 (1989).

19. D. den Engelsen, P. G. Harris, T. G. Ireland, R. Withnall, and J. Silver, ECS J. Solid State Sci. Technol., 2, R201 (2013).

20. X. Jing, T. Ireland, C. Gibbons, D. J. Barber, J. Silver, A. Vecht, G. Fern, P. Trogwa, and D. C. Morton, J. Electrochem. Soc., 146, 4654 (1999).

21. J. Silver, T. G. Ireland, and R. Withnall, J. Electrochem. Soc., 151, H66 (2004).

22. H. E. Hoefdraad, J. Inorg. Nucl. Chem., 37, 1917 (1975).

23. D. den Engelsen, P. Harris, T. Ireland, G. Fern, and J. Silver, Ultramicroscopy, to be published.

24. M. Buijs, A. Meyerink, and G. Blasse, J. Lumin., 37, 9 (1987)

25. A. Bril and F. A. Kröger, Philips Tech. Rev., 12, 120 (1950).

26. L. Wang, N. Liao, L. Shi, H. Jia, P. Du, Z. Xi, and D. Jin, Electrochem. Solid State Lett., 13, E7 (2010).

27. R. S. Loitongbam, W. R. Singh, G. Phaomei, and N. S. Singh, J. Lumin., 140, 95 (2013).

28. Q. Lü, Y. Wu, L. Ding, G. Zu, A. Li, Y. Zhao, and H. Cui, J. Alloys Comp., 496, 488 (2010).

29. Z. Xu, J. Yang, Z. Hou, C. Li, C. Zhang, S. Huang, and J. Lin, Mater. Res. Bull., 44, 1850 (2009). 